\title{
Evolution of Principle and Practice of Electrodeposited Thin Film: A Review on Effect of Temperature and Sonication
}

\author{
A. Mallik and B. C. Ray \\ Department of Metallurgical and Materials Engineering, National Institute of Technology, Rourkela 769008, India \\ Correspondence should be addressed to A. Mallik, archananitrkl@gmail.com
}

Received 30 October 2010; Accepted 19 January 2011

Academic Editor: Boniface Kokoh

Copyright ( $) 2011$ A. Mallik and B. C. Ray. This is an open access article distributed under the Creative Commons Attribution License, which permits unrestricted use, distribution, and reproduction in any medium, provided the original work is properly cited.

\begin{abstract}
This review discusses briefly the important aspects of thin films. The introduction of the article is a summary of evolution of thin films from surface engineering, their deposition methods, and important issues. The fundamental aspects of electrochemical deposition with special emphasis on the effect of temperature on the phase formation have been reviewed briefly. The field of sonoelectrochemistry has been discussed in the paper. The literature regarding the effects of temperature and sonication on the structure and morphology of the deposits and nucleation mechanisms, residual stress, and mechanical properties has also been covered briefly.
\end{abstract}

\section{Thin Film Technology}

One of the major advances in the history of technology, that is, surface engineering, was the knowledge regarding protection of a surface from environmental attack by application of an organic, inorganic, or metallic coating, thereby, extending the life of not just the surface, but the entire component or equipment. The most common reasons for altering the surface are to improve corrosion resistance, control friction and wear, and alter dimension or to alter physical properties (reflection, color, conductivity). As applied to materials, surface engineering may be coatings or special surface treatments. They include processes such as diffusion treatments, selective hardening, plating, hardfacing, thermal spray coatings, high-energy treatments such as laser processing, and organic coatings such as paints and plastic laminates [1-5]. Involvement with coatings dates back to the metal ages of antiquity in gold beating and gilting $[6,7]$ and can be said to have transformed itself from what was mainly an empirical craft, into a key technology, grounded on scientific principles within a span of few decades [8-10]. The advances in coatings are primarily in areas relating to tailor the microstructure or the thickness. The complexity of the tribological properties of materials and the economic aspects of friction and wear justify the increasing research effort in bridging the fields of ultrafine-structured materials and coatings. Thin films are coatings with the thickness value below $1 \mu \mathrm{m}$ and are widely used in microelectronics, optics, and solar cell systems [11-17]. Thin film systems necessitate direct control of materials on the molecular and atomic scale, including surface modifications, deposition, and structuring. There exists a huge variety of thin film deposition processes and technologies which originate from purely physical or purely chemical processes. However, deposition processes for applications in advanced microelectronics and surface engineering processes will require the most demanding approaches in the near future. The more important thin film processes are based on liquid phase chemical techniques, gas phase chemical processes, glow discharge processes, and evaporation methods [18]. Typical processes include ion beam assisted deposition (IBAD) and plasma enhanced chemical vapor deposition (PECVD). Examples for novel thin film processing techniques, which are still under development, include pulsed laser ablation (PLD) and chemical solution deposition (CSD). Both techniques enable the synthesis of complex thin film materials (complex oxides, carbides, and nitrides). The electrodeposition of thin films is a viable alternative to vacuum-based deposition process, such as sputtering, plasma deposition, or chemical vapor deposition. Its major advantages are that processing can 
take place at room temperatures and pressures and thin film properties can be controlled [19-21]. The next section deals with the electrochemical deposition mechanism (electrocrsytallization) which also includes approaches to understand the process towards the fabrication of fine grained films.

\section{Electrochemical Deposition}

The field of electrochemistry encompasses a massive array of different phenomena (e.g., electrophoresis and corrosion), devices (electrochromical displays, electro analytical sensors, batteries, and fuel cells), and technologies (the electroplating of metals and the large-scale production of aluminum and chlorine) [22-25]. The technology of electrochemical deposition of metals and alloys involves the reduction of ions from aqueous, organic, and fused salt electrolysis. The deposition of material species involves reduction of ions in the solution as, $M_{\text {Sol }}^{Z+}+Z e \rightarrow M_{\text {lattice. The seemingly }}$ simple single reaction needs pre- and postcomplex steps $[19,26]$ before contributing to the whole deposition process as depicted in Figure 1. This is a reaction of charged particles at the interface between a solid metal and a liquid solution. The two types of charged particles, an ion and an electron, can cross the interface. Hence, four types of fundamental areas are involved in the due process of deposition: (1) electrode-solution interface as the locus of deposition process, (2) kinetics and mechanism of the deposition process, (3) nucleation and growth processes of the deposits, and (4) structure and properties of the deposits. The consecutive sections are addressed to above points and every facet has been discussed briefly.

2.1. Electrode Solution Interface. The interface between the electrode and the electrolyte is the heart of electrochemistry. It is the place where charge transfer takes place, where gradients in electrical and chemical potentials constitute the driving force for electrochemical reactions. Electrodeposition processes occur in this very thin region, where there is a very high electric field $\left(10^{6}\right.$ or $\left.10^{7} \mathrm{~V} / \mathrm{cm}\right)$. The classical approach describes the electric double layer (EDL) of a metal electrolyte interface by a plate condenser of molecular dimensions [19, 27]. One plate is the metal surface with its excess charge, and the other is formed by the solvated ions at closest approach. The solvated ions that form the outer Helmholtz plane (OHP) and that are held in position by purely electrostatic forces are termed as nonspecifically adsorbed. These are mainly solvated cations. Because of thermal agitation in the solution, the nonspecifically adsorbed ions are distributed in a three-dimensional region called the diffuse layer, which extends from OHP to the bulk of solution. The excess charge density in the diffuse layer is $\sigma^{\mathrm{d}}\left(\mu \mathrm{C} / \mathrm{cm}^{2}\right)$. Most anions, however, give away part of that solvation shell when entering the double layer to form a chemical bond with the electrode surface. These ions are termed specifically adsorbed, and their centers form the inner Helmholtz plane (IHP). The total charge density from specifically adsorbed ions in this inner layer is $\sigma^{\mathrm{i}}$; hence,

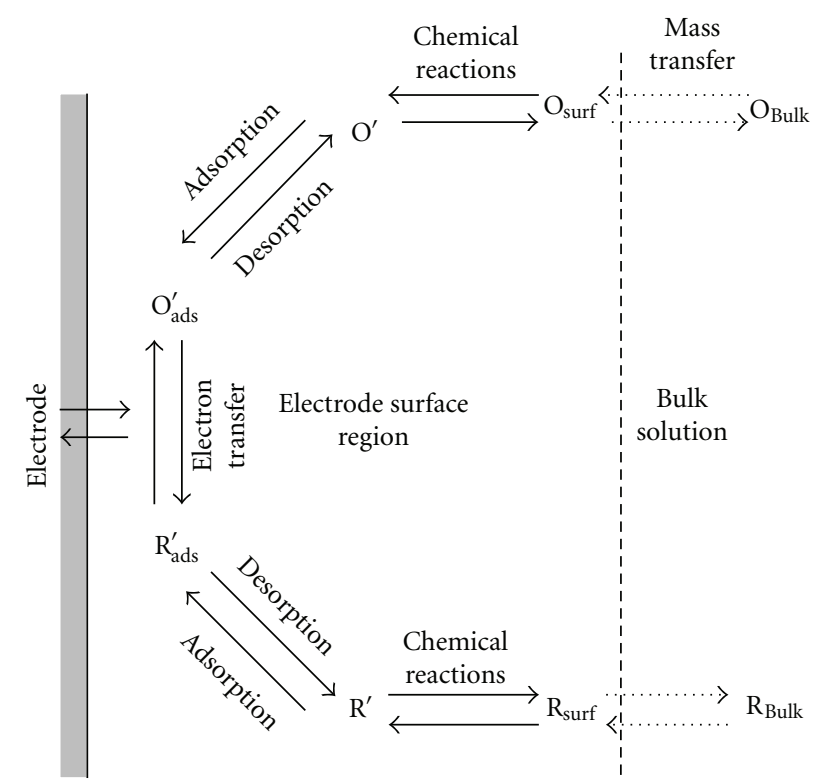

Figure 1: Pathway of a general electrode reaction (see [27]).

the total excess charge density on the solution side of the double layer, $\sigma^{\text {s }}$ is given by

$$
\sigma^{\mathrm{s}}=\sigma^{\mathrm{i}}+\sigma^{\mathrm{d}}=-\sigma^{\mathrm{m}}
$$

The thickness of the diffuse layer depends on the total ionic concentration in the solution; for concentrations greater than $10^{-2} \mathrm{M}$, the thickness is less than $\sim 100 \AA$. The potential profile because of the charge density variation is also shown in Figure 2. The capacitance and the charging currents in the electrochemical system can either be measured by a potential/current step or by ramping the voltage.

\subsection{Thermodynamics and Kinetics of Deposition Mechanism}

2.2.1. Nucleation Work. In the formation and growth of adion clusters, two processes are of fundamental importance: (1) the arrival and adsorption of ions (atoms) at the surface, and (2) the motion of these adsorbed ions (adions, adatoms) on the surface $[19,27]$. An adion deposited on the surface of a perfect crystal stays on the surface as an adion only temporarily since its binding energy to the crystal is small. It is not a stable entity on the surface, but it can increase its stability by formation of clusters. For the formation of a cluster of $N$ ions, the Gibbs energy, $\Delta G(N)$ has two components $[28,29]$

$$
\Delta G(N)=-N \Delta \mu+\varnothing(N)
$$

where the first term is related to the transfer of $N$ ions from a supersaturated $(\Delta \mu)$ solution to the crystal phase and the second term is related to the increase of the surface energy due to creation of the surfaces of a cluster. The transfer of ions is purely a thermodynamic conceptual origin. Under the state of thermodynamic equilibrium in an electrochemical system comprising metal ions in solution, metal adatoms 


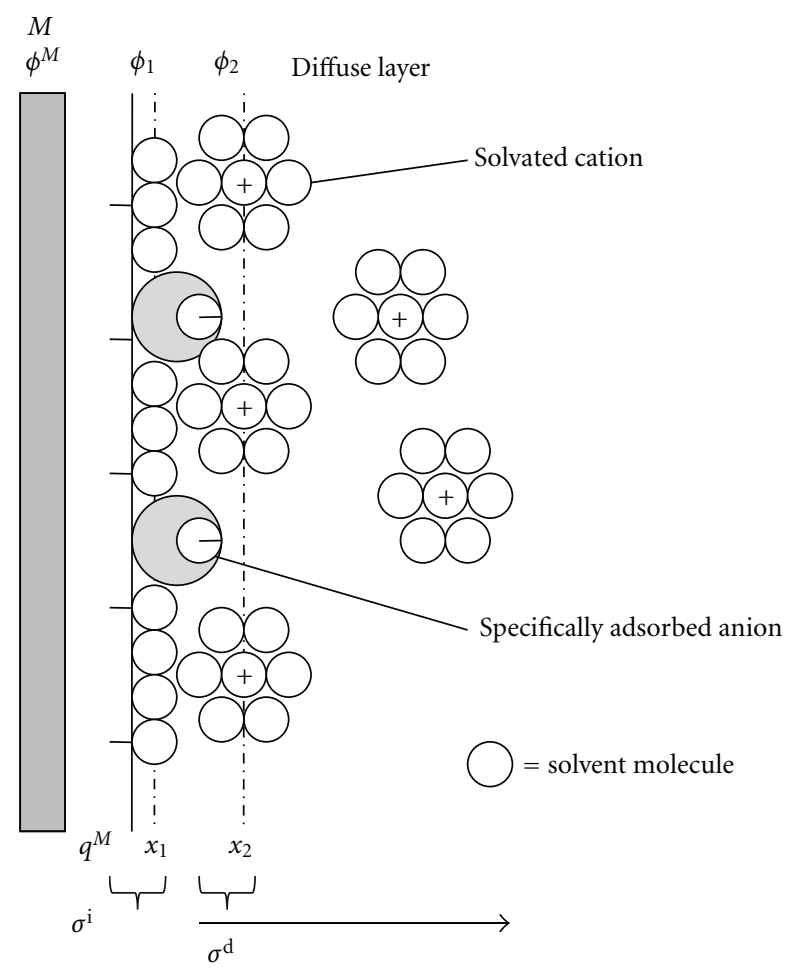

FIGURE 2: Double layer region ([27], reproduced with permission).

on an electrode, and metal atoms in the deposit, the system is stable. The formation, growth, or dissolution of a phase cannot occur in this situation. Favorable conditions for a first-order phase transition, that is, for metal ions discharging either on the crystal or on the substrate, occur when the solution is supersaturated [20]. This means that the electrochemical potential of the electrochemically active species in the parent phase (the electrolyte solution) is larger than the electrochemical potential of the bulk metal. The difference $\Delta \mu=\mu^{\text {sol }}-\mu^{M}>0$ defines the electrochemical supersaturation, which is the thermodynamic driving force and the reason for the nucleus formation to be connected with the overcoming of an energy barrier for the phase transition. Thus, the interrelation between the supersaturation $(\Delta \mu)$ and the size of the critical nucleus $\left(N_{\text {crit }}\right)$ will decide the lowest Gibbs energy of phase formation $\left(\Delta G_{\text {crit }}\right)$ and the highest rate $\left(J=A_{J} \exp \left(\Delta G_{\text {crit }} / B T\right)\right)$ of cluster formation $[20,30]$ at a fixed set of temperature (T) and pressure. $B$ is Boltzmann constant. Different approaches have been established for the estimation of the parameters depending upon the size of the clusters. If adsorption, diffusion, and binding of the clusters are not the limiting factors (for sufficiently large clusters) than $\Delta G_{\text {crit }}$ will have a value [29]

$$
\Delta G_{\text {crit }}=\frac{\Delta \mu N_{\text {crit }}}{\gamma-1}=\frac{1}{\gamma} \varphi X\left(N_{\text {crit }}\right)=\frac{1}{\gamma} \varnothing\left(N_{\text {crit }}\right),
$$

where $\gamma$ is the dimensionality of the cluster and $\varphi$ is specific boundary energy. For small crystals with the dominant effect of binding energies of adatom with substrate as well as bulk phase may have an expression for $\Delta G_{\text {crit }}$

$$
\Delta G_{\text {crit }}=\Delta \mu\left(N_{\text {crit }}+\beta^{*}\right)-\sum \Psi_{i}-N_{\text {crit }}\left(\Psi_{\text {kink }}+\varepsilon\right),
$$

where $\beta^{*}$ denotes the charge transfer coefficient, $\Psi_{i}$ is the binding energy, $\Psi_{\text {kink }}$ is the binding energy of a kink atom, and $\varepsilon$ is the average strain energy per atom. Hence, irrespective of the size of the initial critical nuclei, the increase in supersaturation will explicitly follow a decreasing $N_{\text {crit }}$ trend. Furthermore, in a macroscopic scale, Kardos and Foulke [31] distinguish three possible mechanisms for improved smooth and bright electrodepositions: true leveling, grain refining, and randomization of crystal growth. The indiscriminate deposition on all available surface sites unlike the selective one, on favorable kinks, steps, and the ends of screw dislocations may fulfill the requirements. One of the approaches for such requirements in the process is to employ sufficient supersaturation, by varying both the external and internal deposition parameters.

In order to discuss the means by which an electrolyte can get supersaturated, an idea of possible electrochemical variables which can contribute to the factor needs to be known. The parameters of importance in electrochemical cells are shown in Figure 3. All these variables can be categorized into two broad groups, electrical and nonelectrical parameters. Hence, there may be two possibilities for meeting the supersaturation condition, that is, either to increase the electrochemical overpotential/current/quantity of electricity or the activity of ions by the nonelectrical variables inside the solution. While the phenomenon of overpotential driven supersaturation is quite an established field, the activitydriven supersaturation theories are still unexplored and under scientific conflictions. One such approach may be in the direction of lowering the temperature of the electrolyte to enhance the nucleation phenomenon driven by temperature induced supersaturation. The following section elaborates the process in detail.

2.2.2. Effect of Temperature. It is scarcely surprising that, as the temperature is varied within the wide range available, the properties of all materials undergo considerable modifications. Hence, there are fundamental, analytical, and technological reasons for wanting to extend this temperature range for venturing into the relatively unexplored technology associated with the science $[32,33]$. The technology of low temperature has the aspects of cryophysics, cryobiology, cryosurgery, cryoelectrochemistry, and so on in the discipline [34-36]. Since the last experimentation on cryoelectrochemistry, there has been a renewed interest in the field towards intermediate electrode reactions, electroformation, and electranalysis $[37,38]$ to characterize the temperaturedependent electrode processes that are often of interest themselves; these include: standard electrode potentials, activity coefficients, conductance measurements, equilibrium constants, diffusion activation constants, and the electrodeposition of metals and alloys. Covering all these aspects is beyond the scope of the present paper, and concentration is now on low temperature electrodeposition. The effect of 


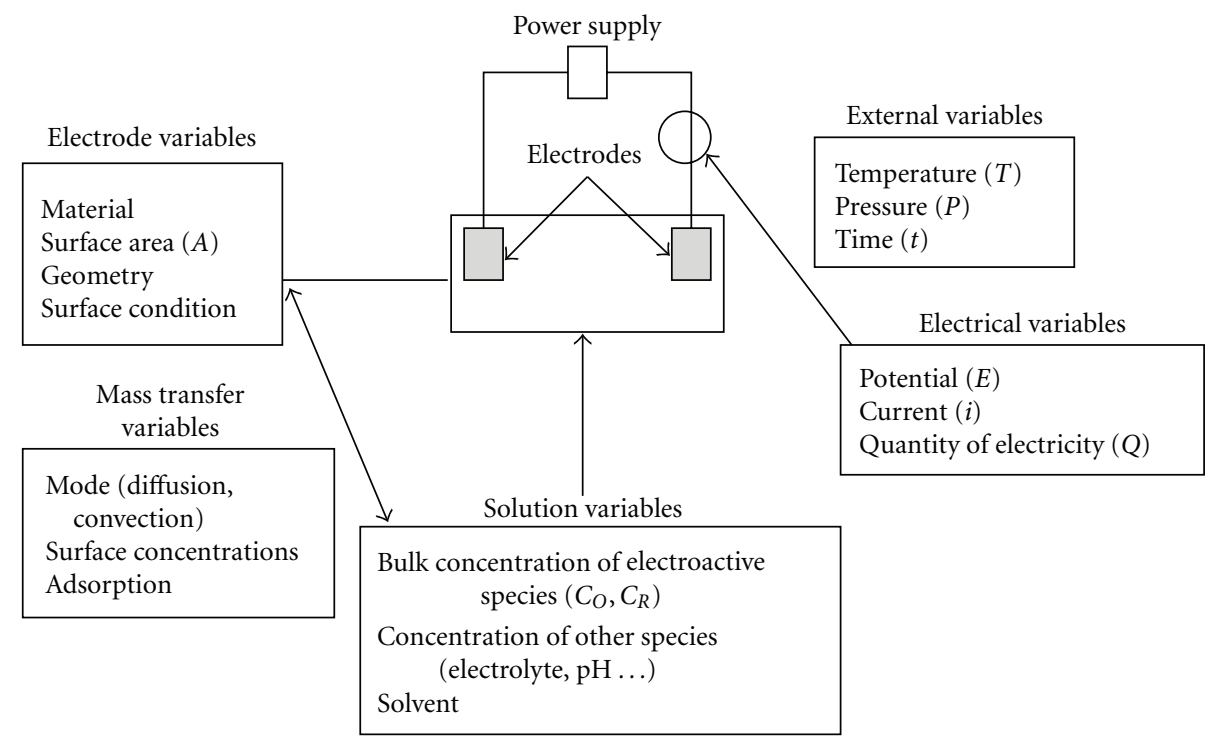

FIGURE 3: Variables affecting electrochemical phase formation (see [27]).

low temperature may have a huge discrimination on the deposit characteristics. The reduction in temperature has resulted in a change in morphology habitat as reported in [39] for Se and $\mathrm{Cu}$ depositions [40]. Grain refinement $[41,42]$ as well as coarsening $[43,44]$ has also been cited in the literature. Porous $[45,46]$ and compact $[39,47]$ deposits have been observed with reduced electrolyte temperature. By enlisting these diversities, there is surely a great research ahead for the seemingly simple but controversial parameter. Let us put forward the temperature-driven effects on the thermodynamics and kinetics of phase formation.

The thermodynamics and kinetics of the electrochemical crystallization may depend on a number of factors. And the existence of an energy barrier makes nucleation a probability process $[20,48]$, with a rate

$$
J_{0}=Z_{0} W \lambda^{-1} \exp \left[\frac{-\Delta G_{\text {crit }}}{k T}\right],
$$

where, $Z_{0} / \mathrm{cm}^{-2}$ is the number density of active sites on the substrate, $\mathrm{W} / \mathrm{s}^{-1}$ is the frequency of attachment of single atoms to the nucleus, $\lambda^{-1}$ is a nondimensional quantity accounting for the difference between the quasiequilibrium and the stationary number of nuclei, $\Delta G\left(n_{c}\right)$ is the maximum energy barrier at a critical cluster size $n_{c}$, and $k$ and $T$ have their usual meanings. The energy barrier that the ions have to surmount for an adatom formation is an obvious function of temperature. Alterations in the temperature range used may affect the kinetics in the following way. Decreasing temperature increases the level of supersaturation. Hence, the activity of ions will increase and the critical nucleating condition will occur at low temperature. The relationship between morphology and degree of supersaturation is an open area of research. However, supersaturation determines the degree of metastability in the parent phase. To relate the nonequilibrium cluster energetic and fluctuational growth to the rate of nucleation, it is necessary to describe the cluster population distribution.
The metastable equilibrium concentration of critical clusters of a given size, $C_{N}$, is then [49]

$$
C_{n}=C_{l} \exp \left[\frac{-\Delta G}{k T}\right]
$$

where $C_{l}$ is the number of atoms per unit volume in the liquid. Thus, a high nucleation rate can be achieved at low temperature.

The growth of clusters past the critical size can be represented kinetically $[20,48]$ as

$$
J=v_{\mathrm{SL}} S_{\text {crit }} C_{n}=\nu \exp \left[\frac{-\Delta H_{d}}{k T}\right] S_{\text {crit }} C_{l} \exp \left[\frac{-\Delta G}{k T}\right],
$$

where $v_{\mathrm{SL}}$ is the jump frequency of atoms form the liquid to the critical cluster (It can be estimated from lattice vibration frequency $v$ and activation energy barrier for interfacial diffusion $\left.\Delta H_{d}\right), S_{\mathrm{cr}}$ is the number of atoms surrounding a cluster, and $C_{n}$ is the number of critical clusters. At low temperature, the population of critical clusters increases whereas the rate of attachment of further atoms to the cluster decreases due to increased diffusion barrier. Hence, temperature can affect the crystal growth by several ways, all of them predominantly resulting in a smaller crystal size at low temperatures. Low temperature is a relative term and varies from system to system. For a metal/alloy depositing bath, the vast majority of low temperature electrodeposition has been limited to $20-25^{\circ} \mathrm{C}$. Yet, Cu electrolyte temperature down to $10^{\circ} \mathrm{C}$ has been maintained but for $\mathrm{Cu}_{2} \mathrm{O}$ depositions [50].

The literature covering the low temperature electrodepositions, however, has descriptions on crystal morphology and less on the surface uniformity aspects and electrochemical analysis. To acquire uniform thickness, adhesion, morphology, and other properties, the uniform spreading of the grains in the deposit is imperative. Hence, the electrochemical system at low temperature needs to have 
an activation to compliment the deposition mechanism to comply the above requirements. Coupling ultrasound to electrochemistry, sonoelectrochemistry, has long been acknowledged towards this respect. A brief review of the mechanism and effects of the parameter is covered in the following section.

\section{Sonoelectrochemistry}

The benefits of coupling ultrasound to electrochemical processes have been recognized and explored for a long time [51-58]. The complexity of the processes induced by power ultrasound $[59,60]$ and the sensitivity of results on conditions and experimental parameters [61] have hitherto prevented ultrasound in electrochemistry, or sonoelectrochemistry, from becoming a reliable and established tool. However, the use of ultrasound in a reaction system provides specific activation based on a physical phenomenon: acoustic cavitation. Cavitation occurs from the alternating longitudinal sound wave creating pressure variations within the liquid media in which the activation of preexisting nuclei form stable or transient bubbles or voids in the liquid structure [62]. Figure 4 shows a representation of cavitation. Leighton characterized a particular type of cavitation in which small bubbles in strong acoustic fields undergo growth to many times their original size and then subsequently undergo rapid collapse [63]. The bubble serves to concentrate the acoustic energy whereby the growth phase is isothermal with the collapse being adiabatic. This is termed transient cavitation which is distinguished from the less energetic stable cavitation where the bubble pulsates about equilibrium over successive acoustic cycles. Because of the cavitation of the liquid, the lists of effects (Figure 5) which can create unusual physical and chemical conditions [64, 65] include (a) acoustic streaming: cavitation bubbles can oscillate around their resonant size and generate velocities that induce shear stresses. It is brought about by the momentum being absorbed by the liquid media, which manifests itself as turbulent flow in the direction of the applied sound field. This is a nonlinear effect [66], which has been suggested to lead to local flow rates of more than $10 \mathrm{~m} \mathrm{~s}^{-1}$ [67]. Figure 6 shows a typical flow pattern such as induced by a sonic horn operating at $20-40 \mathrm{kHz}$ and located near a surface. (b) Hot spot: sudden collapse of bubbles generates momentary high temperatures and pressure in the bubble core. During transient cavitation, energy is focused within the bubble to generate $[63,65,68]$ localized transient high temperatures and pressures estimated at temperatures of $5000^{\circ} \mathrm{C}$ and pressures of 1700 bar with relatively low bulk temperatures. For example, Suslick et al. showed that clouds of collapsing cavitation bubbles produced equivalent temperatures of roughly $5000^{\circ} \mathrm{C}$, pressures of about 1000 atmospheres and heating and cooling rates above $1010 \mathrm{~K} \mathrm{~s}^{-1}[64,68]$. Whilst these estimations may be approximate, experimental measurements suggest that these are not unreasonable and that even higher temperatures may be produced [69-73] in both multibubble and single-bubble cavitation [74, 75]. This effect may bring extremely high level of mass transport, homogenization of the solvent, intermediate reactions [72,
73, 76]. (c) Shock waves: sudden collapse of cavitation bubbles leads to the formation of shock waves. (d) Liquid microjets: collapsing bubbles near a surface experience non-uniformities in their surroundings that results in the formation of high-velocity microjets. Cavitation at the solidliquid interface occurs more readily than in bulk solution, where crevices and active sites exist where vapor bubbles readily form. When transient cavitation occurs near a solid surface such as an electrode, collapse becomes nonspherical driving a high-speed jet into the surface $[77,78]$. This violent impact leads to surface cleaning, ablation, fracture of the solid-liquid interfaces or acoustic emulsification for liquidliquid systems, and depassivation of the electrode surfaces [79].

When applied to electrochemical experiments, ultrasound provides an increased mass transport regime in which the voltammetric response is visibly changed. An excellent review on ultrasonically enhanced voltammetric analysis and applications has been done by Banks and Compton [80]. This section borrows a small excerpt of their report. The forced convection (Figure 6) can be parameterized with the knowledge that ultrasonic application results in a truncated or thinned Nernst diffusion layer [81]. The diffusion layer model (Figure 7) allows a naive description of the mass transport at the electrode interface by assuming a laminar sublayer close to the surface and an approximately linear concentration gradient across a thin layer adjacent to the electrode. Equation (8) best describes transport to an insonated electrode based on the uniformly accessible electrode model $[67,82]$

$$
I_{\lim }=\frac{n F D A c_{\text {bulk }}}{\delta}
$$

where the limiting current, $I_{\text {lim }}$, is related to the number of transferred electrons, $n$, the Faraday constant, $F$, the diffusion coefficient, $D$, the electrode area, $A$, the concentration, $c$, and the diffusion layer thickness, $\delta$. For a geometry in which the electrode is face-on to the horn in aqueous media it has been found experimentally that [83]: $\delta \propto D^{2 / 3}$. This is a general feature of convective systems and suggests that the diffusion layer is not purely stagnant as suggested by Nernst model but contains a convective component. Experiments conducted in a face on geometry [67] in aqueous solution have shown that: $\delta \propto D^{1 / 3} A[X]$, suggesting that an insonated system behaves as a hydrodynamic electrode [84]. Moriguchi [85] is thought to have first drawn attention to the fact that ultrasound decreases the thickness of the diffusion layer, although Marken et al. [67] and Cooper and Coury [86] proposed independently that acoustic streaming provides the major contribution of the possible ultrasonic mechanisms on the rate of mass transport to an electrode. In view of the above effects, ultrasound can have multiple impacts on the crystallization process as listed below.

3.1. Sonocrystallization. Crystallization under sonication may be referred as sonocrystallization. Using ultrasound to generate nuclei in a relatively reproducible way provides a well-defined start point for the crystallization process and allows the developer to focus on controlling the crystal 


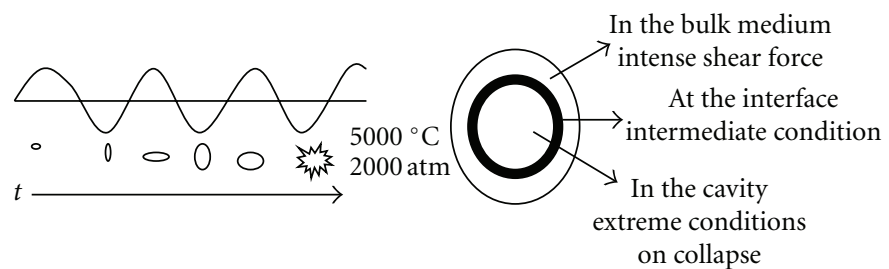

FIGURE 4: Formation of a cavitation bubble by ultrasound.

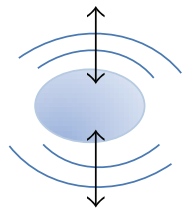

Acoustic streaming

(a)

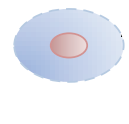

Hot spot

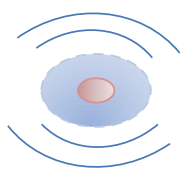

Shock wave

(c)

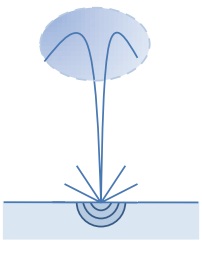

Micro-stream etting

(d)
FIGURE 5: Effects of acoustic cavitation in the liquid medium ([56], reproduced with permission).

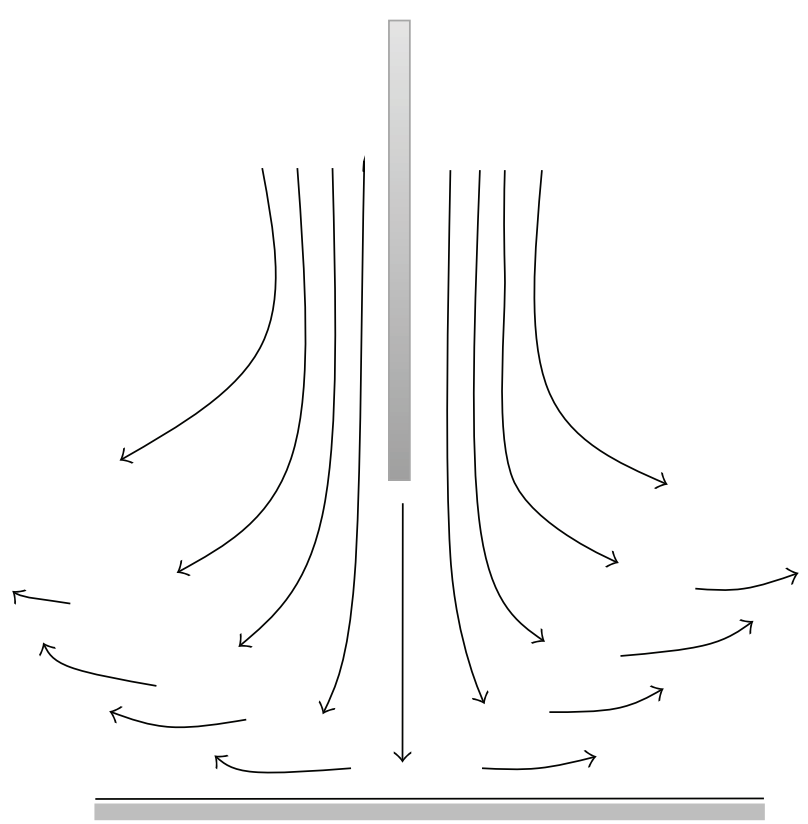

Figure 6: Acoustic streaming: A typical flow pattern induced by a sonic horn ([80], reproduced with permission).

growth for the remainder of the residence time in the crystallizer. This approach has been used successfully to manipulate crystal size distribution, solid-liquid separation behaviour, washing and product purity, product bulk density, and powder flow characteristics. Hence, ultrasound can be used beneficially in several key areas of crystallization such as [8790] the following:

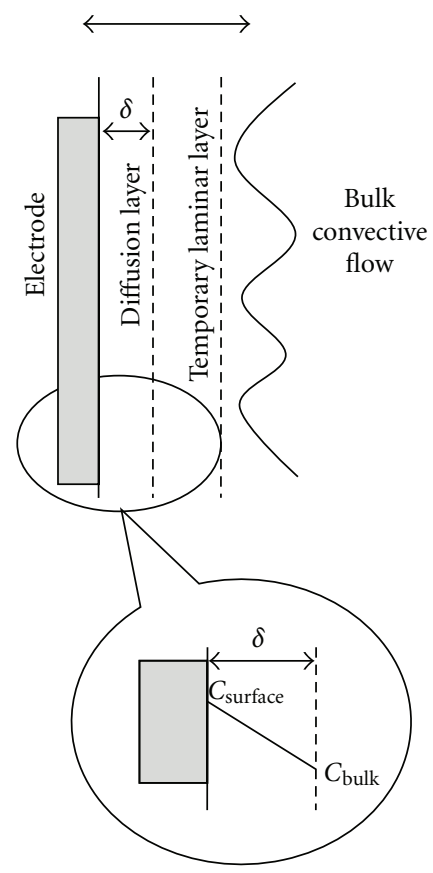

FIGURE 7: Schematic representation of the diffusion and boundary layers at the electrode-solution interface as applied in the diffusion layer model ([80], reproduced with permission).

(i) initiation of primary nucleation and narrowing down the metastable zone width,

(ii) crystal habit and perfection,

(iii) reduced agglomeration,

(iv) a noninvasive alternative to the addition of seed crystal (seeding) in sterile environment,

(v) manipulation of crystal distribution by controlled nucleation.

All these effects are function of ultrasonic parameters such as frequency of oscillations, intensity of irradiation, and physical properties of the liquid. Furthermore, electrodeposition in presence of ultrasound may have effects on the reaction kinetics as well as on the deposits in terms of appearance, adherence, grain morphology, and habitats. Remarkable increase in mass transport, the most distinct effect of cavitation, enables it to modify a diffusion controlled system to a charge transfer system [91, 92]. To cite the effects on deposit are, reduction in grain size [93], change in grain orientation with wave orientation [94], particle 
agglomeration and increased dispersion [95, 96], brighter surface [97] and reduction in residual stress, and hence good adhesion $[94,98]$ have been observed at constant frequency and power output. While with varying frequency and intensity, inconsistent fluctuations in the deposit behavior have also been cited in the literature [94, 99]. Ultrasound capable of creating zones of extremely high level of localized supersaturation (due to the high cooling rates in microscopic regions, when bubbles burst) should trigger the nucleation process as observed in the above-mentioned effects. Now the question arises: is the level of supersaturation only which has can result such remarkable change in morphology? In the process of growth, however, high indexed surface zones are transformed into atomically smooth equilibrium faces. Further phase formation needs the formation of new steps or irregularities on the substrate's surface for nucleation $[100,101]$. Crystal fragmentation by ultrasound may create new steps on the defect free crystal face to further supplement the crystallization process. Thus, ultrasonic energy is believed to stimulate a biphasic nucleation sequence, that is, primary (on the native substrate) and secondary (on the existing primary clusters) $[102,103]$. Though a limited literature has been reported on the aspects of ultrasoundinduced secondary nucleation, there is an urgent pressing need of information particularly related to electrochemical phenomena.

The investigations of the effects of ultrasound and low temperature have been restricted to morphological and structural analysis. However, some aspects of redox kinetics have also been covered [104, 105], but there is a serious lack of electrochemical characterization of nucleation and growth at such low temperatures. With a knowledge of the best possible effects of the two parameters on the deposition mechanism and hence the structure and properties of the films, the next section will cover the analytical electrochemical techniques used for both qualitative and quantitative analysis of the electrocrystallization phenomenon.

\section{Nucleation and Growth Analysis}

The continued growth of nuclei of electrodepositing species can only take place by a Faraday process, and the observed current is thus an exact measure of the combined rate of nucleation and growth of the mature nuclei or crystallites. A variety of current-potential-time relationships can be explored, and any particular experiment can be exactly repeated many thousands of times to give the mean values and also the statistical variance of the results. Thus, either deterministic or stochastic descriptions of nucleation are amenable to experimental study by electrochemical means. The experimental study of electrochemical nucleation has been based on the observed response of a conducting substrate to a variety of imposed wave forms. Linear sweep voltammetry and cyclic voltammetry invariably indicate the presence of nucleation, mainly in a qualitative way. The current step method and most widely used single (and also the double) potential step potentiostatic are useful means of quantitative detection of the process of nucleation.
4.1. Cyclic Voltammetry. Cyclic voltammetry is a very versatile electrochemical technique which allows us to probe the mechanics of redox and transport properties of a system in solution $[27,106]$. The potential scan with a typical cyclic voltammogram is shown in Figure 8. The magnitude of the observed Faradaic current can provide information on the overall rate of the many processes occurring at the working electrode surface. As is the case for any multistep process, the overall rate is determined by the slowest step. In general, the electrode reaction rate is governed by the rates of processes such as the following:

(1) mass transfer (e.g., of $O$ from the bulk solution to the electrode surface),

(2) electron transfer at the electrode surface,

(3) chemical reactions preceding or following the electron transfer, and these might be homogeneous processes (e.g., protonation or dimerization) or heterogeneous ones (e.g., catalytic decomposition) on the electrode surface,

(4) other surface reactions, such as adsorption, desorption, or crystallization (electrodeposition).

The simple electrodeposition reactions are far from the control of chemical and surface reactions, and the kinetics is mainly controlled by either mass transport or charge transfer reactions. If, for example, an electrode process involves only fast heterogeneous charge-transfer kinetics and mobile, reversible, homogeneous reactions, we will find below that (a) the homogeneous reactions can be regarded as being at equilibrium and (b) the surface concentrations of species involved in the faradaic process are related to the electrode potential by an equation of the Nernst form. The net rate of the electrode reaction, $v_{r \times n}$ is then governed totally by the rate at which the electroactive species is brought to the surface by mass transfer, $v_{\mathrm{mt}}: v_{r \times n}=$ $v_{\mathrm{mt}}=i / n F A$. Such electrode reactions are often called reversible or Nernstian, because the principal species obey thermodynamic relationships at the electrode surface. If the overall reaction is not mass transport, then the sluggish electron transfer, irreversible will take the control of the kinetics. Since mass transfer and charge transfer play big role in electrochemical dynamics, we review here its three modes and begin a consideration of mathematical methods for treating them.

4.1.1. Reversible Redox System. Mass transport processes are involved in the overall reaction. Mass transfer, that is, the movement of material from one location in solution to another, arises either from differences in electrical or chemical potential at the two locations or from movement of a volume element of solution. The modes of mass transfer are as follows.

(1) Migration. Movement of a charged body under the influence of an electric field (a gradient of electrical potential). 


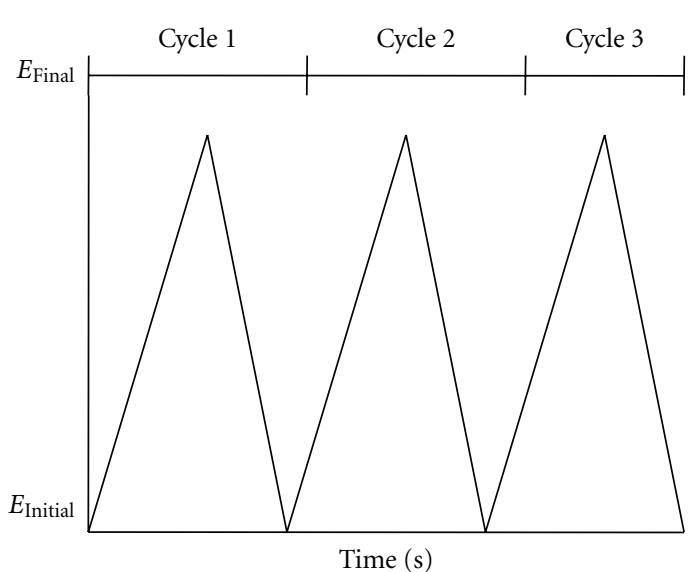

(a)

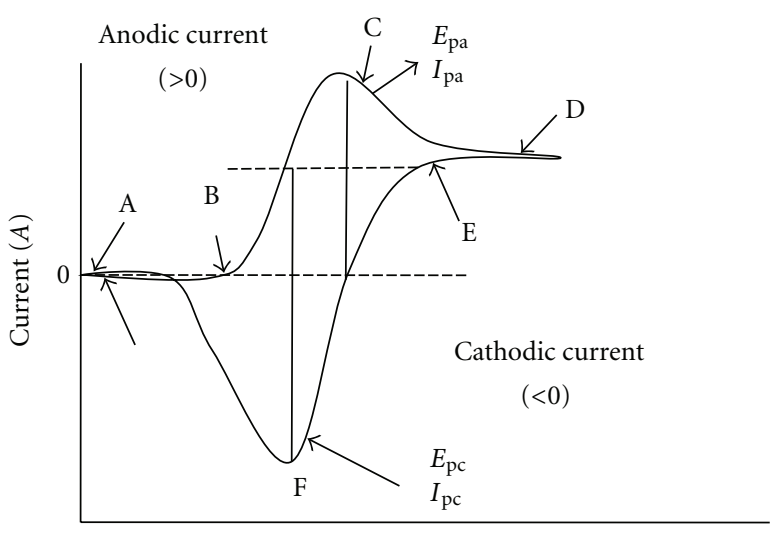

Potential $(V)$

(b)

FIGURE 8: (a) A cyclic voltammetry potential wave form with switching potentials and (b) the expected response of a reversible redox couple during a single potential cycle.

(2) Diffusion. Movement of a species under the influence of a gradient of chemical potential (i.e., a concentration gradient).

(3) Convection. Stirring or hydrodynamic transport. Generally fluid flow occurs because of natural convection (convection caused by density gradients) and forced convection and may be characterized by stagnant regions, laminar flow, and turbulent flow.

Mass transfer to an electrode is governed by the NernstPlanck equation, written for one-dimensional mass transfer along the $x$-axis as

$$
J_{i}(x)=D_{i} \frac{\partial C_{i}(x)}{\partial x}-\frac{z_{i} F}{R T} D_{i} C_{i} \frac{\partial \varnothing(x)}{\partial x}+C_{i} v(x),
$$

where $J_{i}(x)$ is the flux of species $i$ at distance $x$ from the surface, $D_{i}$ is the diffusion coefficient, $d C_{i}(x) / d x$ is the concentration gradient at distance $x, \partial \varnothing(x) / \partial x$ is the potential gradient, $z_{i}$ and $C_{i}$ are the charge (dimensionless) and concentration of species $i$, respectively, and $v(x)$ is the velocity with which a volume element in solution moves along the axis. For the oxidation reaction involving $n$ electrons, Red $\rightleftarrows \mathrm{Ox}+n \mathrm{e}^{-}$: the Nernst Equation gives the relationship between the potential and the concentrations of the oxidized and reduced form of the redox couple at equilibrium (at $298 \mathrm{~K}$ )

$$
E=E^{0^{\prime}}+\frac{0.059}{n} \log _{10} \frac{[\mathrm{Ox}]}{[\mathrm{Red}]},
$$

where $E$ is the applied potential and $E^{O^{\prime}}$ is the formal potential. Note that the Nernst equation may or may not be obeyed depending on the system or on the experimental conditions. Providing that the charge-transfer reaction is reversible, that there is no surface interaction between the electrode and the reagents, and that the redox products are stable (at least in the time frame of the experiment), the ratio of the reverse and the forward current $i_{\mathrm{pr}} / i_{\mathrm{pf}}=1.0$ (in Figure $2 i_{\mathrm{pa}}=i_{\mathrm{pf}}$ and $i_{\mathrm{pc}}=i_{\mathrm{pr}}$ ). In addition, for such a system, the following can be shown.

(1) The expression of the peak current $(A)$ for the forward sweep in a reversible system at $298 \mathrm{~K}$ is given by the Randles-Sevcik equation

$$
i_{\mathrm{pf}}=\left(2.69 \times 10^{5}\right) n^{3 / 2} A D^{0.5} v^{0.5} C^{*},
$$

where $n$ is the number of electron equivalent exchanged during the redox process, $A$ the active area of the working electrode, $D$ and $C^{*}$ is the diffusion coefficient and the bulk concentration of the electroactive species respectively, and $v$ is the voltage scan rate.

(2) The corresponding peak potentials $E_{\mathrm{pa}}$ and $E_{\mathrm{pc}}$ are independent of scan rate and concentration.

(3) The formal potential for a reversible couple $E^{0^{\prime}}$ is centered between $E_{\mathrm{pa}}$ and $E_{\mathrm{pc}}$

$$
E^{0^{\prime}}=\frac{\left(E_{\mathrm{pa}}+E_{\mathrm{pc}}\right)}{2} .
$$

(4) The separation between peaks is given by

$$
\Delta E_{p}=E_{\mathrm{pa}}-E_{\mathrm{pc}}=2.3 \frac{R T}{n F}=\frac{59}{n} \mathrm{mV}, \quad\left(\text { at } 25^{\circ} \mathrm{C}\right)
$$

for a $n$ electron transfer reaction, at all scan rates. However, the measured value for a reversible process is generally higher due to uncompensated solution resistance and nonlinear diffusion. Larger values of $\Delta E_{p}$, which increase with increasing scan rate, are characteristic of slow electron transfer kinetics.

(5) It is possible to relate the half-peak potential $\left(E_{p / 2}\right.$, where the current is half of the peak current) to the polarographic half-wave potential

$$
E_{1 / 2}: E_{p / 2}=E_{1 / 2} \pm \frac{29}{n} \mathrm{mV}
$$

The sign is positive for a reduction process.

(6) The difference between $E_{p}$ and $E_{p / 2}$

$$
E_{p}-E_{p / 2}=\left(2.2 \frac{R T}{n F}\right)=\frac{56.5}{n} \mathrm{mV} \quad\left(\text { at } 25^{\circ} \mathrm{C}\right) .
$$


4.1.2. Irreversible and Quasireversible System. When the rate determining process is the charge transfer reaction the theory of metal deposition is based generally on the Butler-Volmer $[27,107-110]$ equation giving the current density on a metal substrate as function of overvoltage $\eta$

$$
i=F A k^{0}\left[C_{O}(0, t) e^{-\alpha f\left(E-E^{0^{\prime}}\right)}-C_{R}(0, t) e^{(1-\alpha) f\left(E-E^{0^{\prime}}\right)}\right],
$$

where $A$ is the electrode surface area, $k^{0}$ is standard heterogeneous rate constant, $C_{O}(0, t)$ and $C_{R}(0, t)$ is concentration of oxidizing species at the electrode surface at time $t$ respectively, $f=F / R T, E$ is the potential of an electrode versus a reference, $E^{0^{\prime}}$ is formal potential of an electrode, and $\alpha$ is the charge transfer coefficient. For such irreversible processes (those with sluggish electron exchange), the individual peaks are reduced in size and widely separated. Totally irreversible systems are characterized by a shift of the peak potential with the scan rate

$$
E_{p}=E^{0}-\left(\frac{R T}{\alpha n_{a} F}\right)\left[0.78-\ln \left(\frac{k^{0}}{D^{0.5}}\right)+\ln \left(\frac{\left(\alpha n_{a} F v\right)}{R T}\right)^{0.5}\right] .
$$

Thus, $E_{p}$ occurs at potentials higher than $E^{\circ}$, with the overpotential related to $k^{0}$ (standard rate constant) and $\alpha$. Independent of the value $k^{0}$, such peak displacement can be compensated by an appropriate change of the scan rate. The peak potential and the half-peak potential $\left(\right.$ at $25^{\circ} \mathrm{C}$ ) will differ by $48 / \alpha n \mathrm{mV}$. Hence, the voltammogram becomes more drawn-out as $\alpha n$ decreases. The peak current is given by

$$
i_{p}=\left(2.99 \times 10^{0.5}\right) n\left(\alpha n_{a}\right)^{0.5} A C D^{0.5} \nu^{0.5},
$$

where $n_{a}$ is the number of electrons involved in the reaction. The current is still proportional to the bulk concentration, but will be lower in height (depending upon the value of $\alpha$ ). Assuming $\alpha=0.5$, the ratio of the reversible-to-irreversible current peaks is 1.27 (i.e., the peak current for the irreversible process is about $80 \%$ of the peak for a reversible one). For quasireversible systems (with $10^{-1}>k^{\circ}>10^{-5} \mathrm{~cm} / \mathrm{s}$ ) the current is controlled by both the charge transfer and mass transport. The shape of the cyclic voltammogram is a function of the ratio $k^{\circ} /(\pi \nu n F D / R T)^{1 / 2}$. As the ratio increases, the process approaches the reversible case. For small values of it, the system exhibits an irreversible behavior. Overall, the voltammograms of a quasireversible system are more drawn out and exhibit a larger separation in peak potentials compared to a reversible system.

Unlike the CVs shown in Figure 8, certain cyclic voltammograms may have single or multiple cross-over points in between forward and reverse scans as shown in Figure 9. The cross-overs in cathodic and anodic branches are predominant in reversible systems involving undissolved products at cathode, for example, nucleation and growth of metallic deposits at cathode. Deposition potential of metallic ions on a foreign substrate is usually higher than deposition potential on the electrode made of the same metal due to crystallographic substrate-metal misfit. Therefore, deposition on

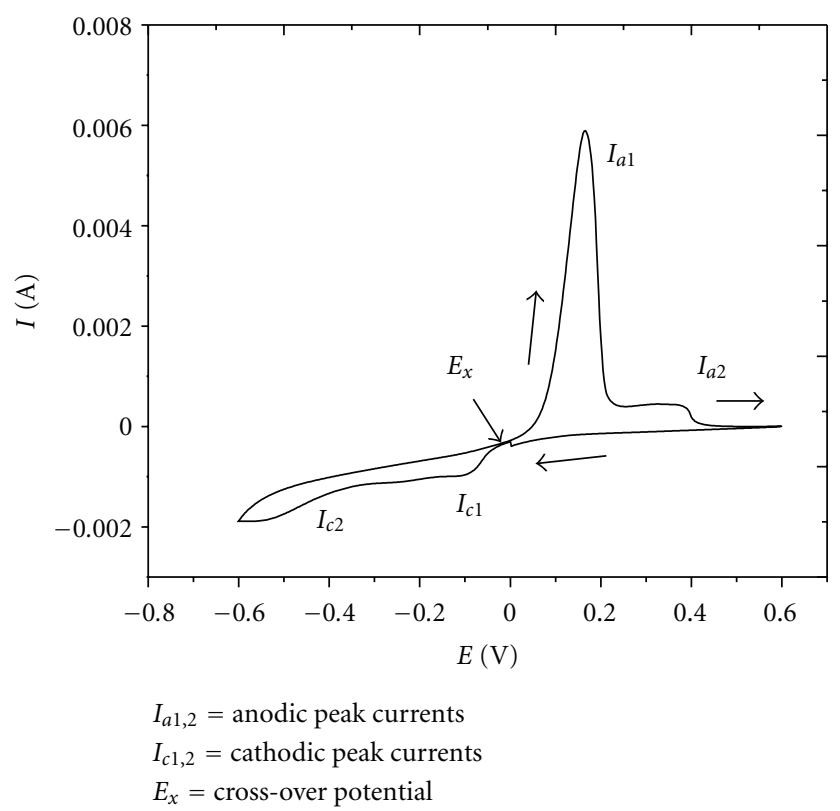

(a)

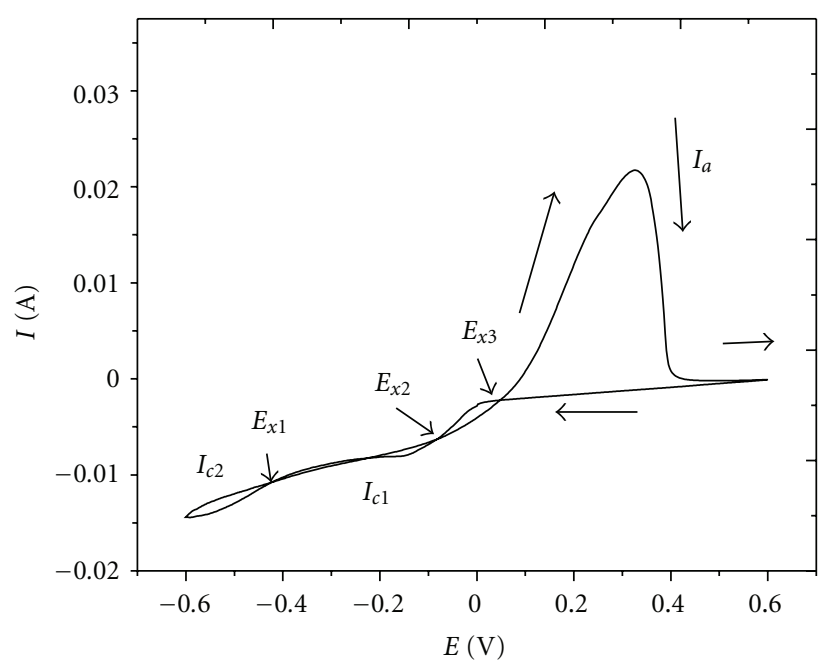

$I_{a}=$ anodic peak current

$I_{c 1,2}=$ cathodic peak currents

$E_{x 1,2,3}=$ cross-over potentials

(b)

FIGURE 9: Cyclic voltammograms with (a) single and (b) multiple cross-over potentials.

foreign electrodes commences at potentials that are more negative compared with the redox potential of $M / M^{n+}$. In the anodic direction, however, the oxidation of metal ion starts from the surface that already has deposited metal, resulting in a potential close to the $M / M^{n+}$ equilibrium potential. Due to the difference in deposition and dissolution potentials, a cross-over occurs between the cathodic and anodic current traces $[111,112]$ at the cross-over potential Ex. Hence the presence of the cross-over is diagnostic for the nuclei 


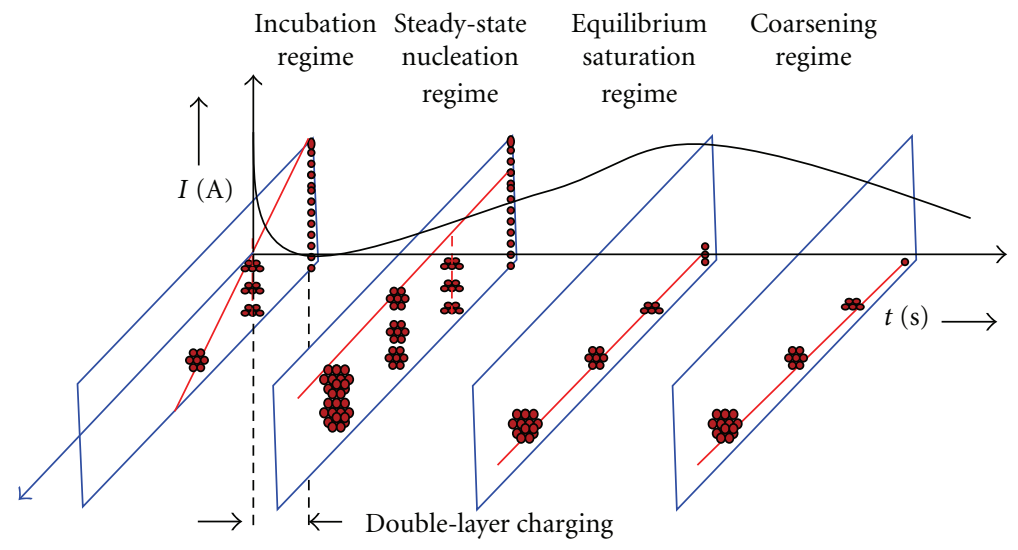

Figure 10: A typical chronoamperogram.

formation on the electrode. Multiple cross-over points may indicate nucleation mechanisms involving complex chemical reactions [113].

4.2. Potential Step Technique (Chronoamperometry). Potentiostatic transients or chronoamperograms can be made the basis of the evaluation of induction times, nucleation rate constants, nuclear number densities and the mode of nuclei apperance. A typical current-time transient for nucleation with overlapping is shown in Figure 10. The principal nature of the transient is the falling current $\left(I_{d l}\right)$, then a rising section $\left(I_{\max }\right)$ and again a falling section corresponding to double layer charging, nuclei appearance on the substrate and the subsequent growth of electroactive area as established nuclei grow. The earliest work on this "constant overvoltage" for studying the nucleation and growth of electrodeposited materials were done by researchers such as Pangarov and Rashkov [114] and Fleischmann and Thirsk [115]. The current-time transients they recorded showed maxima [115], followed by approximately exponential decay, which suggested that the nuclei were formed according to the equation

$$
\frac{d N}{d t}=A N_{0} e^{(-A t)}
$$

where $t$ is the time since the potential was applied, $N$ is the number of nuclei, $N_{0}$ is the saturation nucleus density (number of active sites), and $A$ is the nucleation rate constant (a potential dependent constant with units of nuclei $\mathrm{s}^{-1}$ ). This nucleation rate law is of great significance, as it is assumed as a basis for an entire family of more sophisticated models developed for the analysis of the process.

Theoretical modeling started with the estimation of nucleation current for a single spherical nucleus growing under planar diffusion [116] and then development and improvement of the models for multiple nucleations with overlapping diffusion zones. An excellent review covering all these models and the gradual development of new models can be followed in [26]. However, all the modified theories could put light only on the decaying current tail of the transient (growth), nucleation current being unchanged.

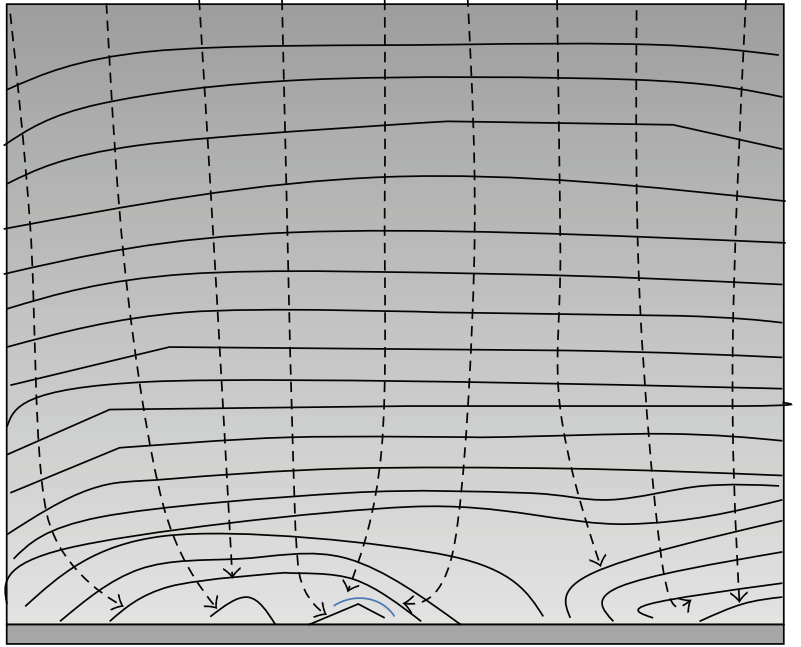

FIGURE 11: Diffusion zones around growing nuclei ([26], reproduced with permission).

Hence, here we will describe the phase formation technique based on the SH model [117]. Their work lies on the simplification of the multidimensional diffusion field on the growing nuclei to two dimensional cases (Figure 11) and hence application of Avrami's theorem of phase formation can be feasible. The theorem describes as

$$
\theta=1-e^{\left(-\theta_{e x}\right)}
$$

where $\theta$ is the actual fraction of surface covered and $\theta_{e x}$ is the fraction of area covered by diffusion zones without taking overlap into account if the $N$ centers are randomly distributed on the electrode surface. Avrami's theorem allowed Scharifker and Hills to relate the radial flux density through the real diffusion zones to an equivalent diffusive flux to an electrode of area $A$. By applying a mass/current balance and then integrating for the instantaneous or progressive cases, expressions can be derived for the total current with respect to time. The current expressions along with other kinetic parameter expressions are given in Table 1. 
TABLE 1: Current expressions and their kinetic parameters from SH model.

Instantaneous nucleation

$I=\frac{z F D^{1 / 2} c}{\pi^{1 / 2} t^{1 / 2}}[1-\exp (-N \pi k D t)]$

$$
\begin{gathered}
I=\frac{z F D^{1 / 2} c}{\pi^{1 / 2} t^{1 / 2}}\left[1-\exp \left(-\frac{A N_{\infty} \pi k^{\prime} D^{2}}{2}\right)\right] \\
t_{m}=\left(\frac{4.6733}{A N_{\infty} \pi k^{\prime} D}\right)^{1 / 2}
\end{gathered}
$$

$t_{m}=\frac{1.2564}{N \pi k D}$

$\underline{I_{m}^{2} t_{m}=0.1629(z F C)^{2} D}$

$I_{m}^{2} t_{m}=0.2598(z F C)^{2} D$

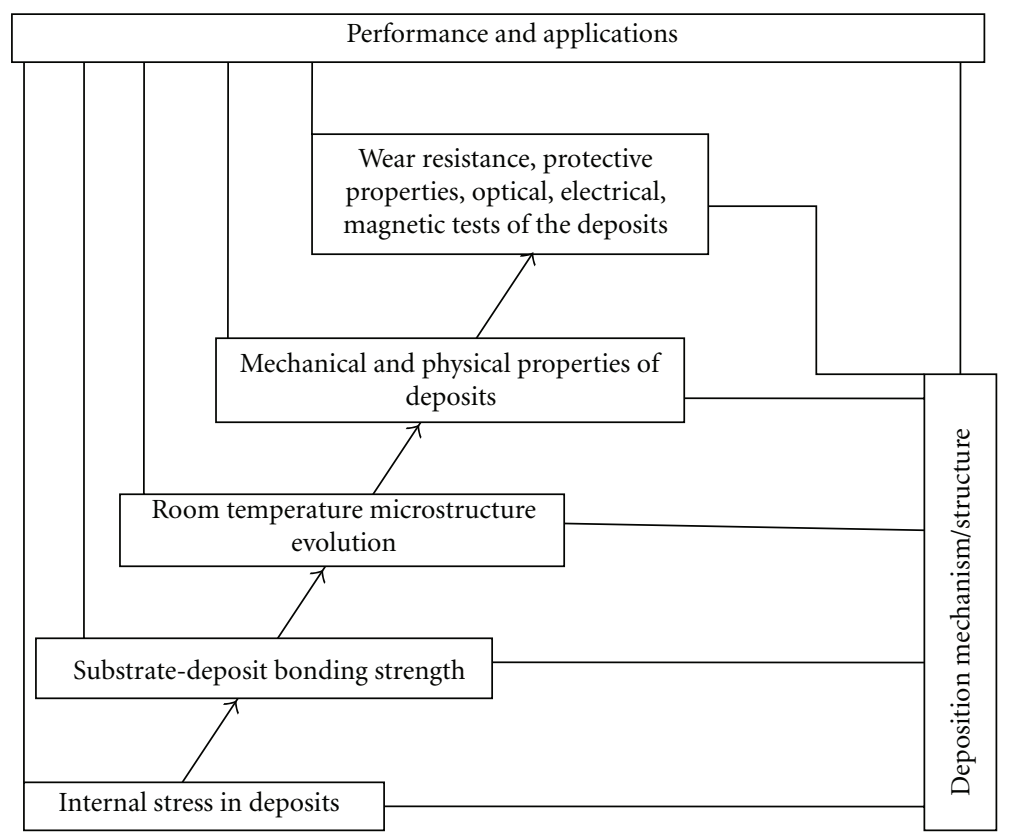

FIGURE 12: Scheme of complex studies of the base metal-coating composition.

\section{Structure and Property Correlation}

As engineering coatings and thin films continue to increase in structural complexity and industrial importance, the need for accurate assessment of the mechanical and physical properties also increases. The deposition of such coatings inherently modifies the microstructure of the coating, resulting in mechanical properties of the coating that may differ significantly from those of the starting material from which the coating was produced $[118,119]$. In addition, residual stresses are often present in the film thickness and are strongly dependent upon deposition method and coating thickness $[120,121]$. These stresses can lead to failure of the component owing to cracking or interface delamination. Another parameter which may affect the final performance of the films is ex-situ growth of the grains. As-deposited, the film grains are fine and equiaxial with a narrow statistical distribution of grain size; however, it is noted that the nano-sized as-plated grains are metastable even at room temperature. The grain size will increase to several microns over a period of time ranging from hours to weeks after deposition. This commonly observed phenomenon is variously referred to as self-annealing, roomtemperature recrystallization or grain growth [122-124]. Since the grain size and texture of polycrystalline films have substantial impacts on their electrical and mechanical properties, it is, therefore, of scientific and technological interest to study the microstructural evolution of deposited films under different processing parameters. It has been observed that phenomenon is very dependent on the deposition parameters, and, hence, on the microstructure of the as-deposited film. Thus, it is clear that in order to maximize coating performance, the microstructure evolution, stress state and mechanical properties of the coating must be well characterized. Comprehensive research of the base metal-coating composition is based on the interrelation of structure, properties, and performance as shown in Figure 12. When moving upwards from step by step, a researcher may consider each previous step as a basis for transition to the next, higher step bringing him closer to estimate the final performance. 


\section{Concluding Remarks}

Small is not only beautiful but also eminently useful. The burgeoning interest is amply justified by the unique properties of ultrafine grained materials and by the promises these systems hold as components of optical, electrical, optoelectrical, magnetic, magneto-optical, and catalytic sensors and devices. The synthesis of these materials for industry has resulted in a tremendous increase in innovative thin film processing technologies. Numerous methods have been applied to fabricate thin films. While each method has its own advantages and disadvantages, electrochemistry has reached sufficient maturity and sophistication to be used for the deposition of fine-structured films. Fundamentally, electrodeposition can yield grain sizes in the nano-crystalline range when the electrodeposition variables (e.g., bath composition, $\mathrm{pH}$, temperature, current density) are chosen such that nucleation of new grains is favourably enhanced in compared to the growth of existing grains. Size reduction of the crystals based upon low temperature of formation is fast becoming popular due to "clean" synthesis. At low temperature, the population of critical clusters, that is, nucleation increases whereas the rate of attachment of further atoms (growth of nuclei) to the cluster decreases due to increased diffusion barrier. The aspects of low temperature electrochemistry did develop as cryoelectrochemistry [125]. Cryoelectrochemistry (at around $-70^{\circ} \mathrm{C}$ ), however, has been limited to electrochemical analysis in nonpolar solvents [126-128] and has rarely been investigated for aqueous solutions and electrochemical synthesis. Studies have been limited to synthesis of insoluble products to as low as $10^{\circ} \mathrm{C}$ [50]. The reports have mainly enlisted the effects of the parameter either on the morphological and property variations or the electrochemical analysis. Relation of the structural and morphological evolution with the nucleation mechanism is not clearly understood and, therefore, needs to be explored.

Though nucleation will be favored at low temperatures of deposition, the film continuity may get impeded due to poor uniformity of the deposition. Synergistic interactions of ultrasound and low temperature can be apparent in this dearth in terms of good surface coverage, adherence, appearance, and stability of films. Ultrasound has been found to be beneficial by (i) causing extremely fast mass transport, (ii) enhancing the mixing and dissolution kinetics at low temperature, and (iii) affecting the formation of solid products at the electrode surface. Experimental evidence of beneficial effects of ultrasound in low-temperature electrochemical system has been proposed by various authors [129131]. Like the silent processes at low temperature, these investigations have been restricted to processes involving the study of mass transport and cavitational effects of $20 \mathrm{kHz}$ ultrasound in non-aqueous electrolytes. Some authors have also reported [132] the electrosynthesis at that low temperature, yet their work was mainly focused on electrochemical quantifications as the system of study was on a soluble final product. However, to the best of our knowledge, no specific prior work has been carried out on deposition formation at low temperatures, though the ample literature is available on the effects of this parameter on structure and properties of deposits at room and high temperatures $[133,134]$.

The pace and progress of developments is increasing a space in use of low bath temperature and ultrasound towards thin film synthesis. Systematic complete investigation of nucleation and growth processes, solid state reactions, structural variation, the thermal and mechanical stability of thin film systems, and phase boundaries is needed to improve the basic understanding of the process.

\section{Acknowledgment}

The authors would like to express deep gratitude and thanks to the National Institute of Technology, Rourkela (NITR) for providing the necessary financial and infrastructural supports.

\section{References}

[1] H. A. Jehn, "Multicomponent and multiphase hard coatings for tribological applications," Surface and Coatings Technology, vol. 131, no. 1-3, pp. 433-440, 2000.

[2] M. Zubielewicz and A. Królikowska, "The influence of ageing of epoxy coatings on adhesion of polyurethane topcoats and protective properties of coating systems," Progress in Organic Coatings, vol. 66, no. 2, pp. 129-136, 2009.

[3] A. W. Ruff and K. G. Kreider, "Deposited thin-film wear sensors: materials and design," Wear, vol. 203-204, pp. 187195, 1997.

[4] J. W. Seok, N. M. Jadeed, and R. Y. Lin, "Sputter-deposited nanocrystalline $\mathrm{Cr}$ and $\mathrm{CrN}$ coatings on steels," Surface and Coatings Technology, vol. 138, no. 1, pp. 14-22, 2001.

[5] A. Basu, J. Chakraborty, S. M. Shariff et al., "Laser surface hardening of austempered (bainitic) ball bearing steel," Scripta Materialia, vol. 56, no. 10, pp. 887-890, 2007.

[6] L. B. Hunt, "The oldest metallurgical handbook," Gold Bulletin, vol. 9, pp. 24-31, 1976.

[7] O. Vittori, "Pliny the elder on gilding," Gold Bulletin, vol. 12, pp. 35-39, 1979 .

[8] L. I. Tushinsky, I. Kovensky, A. Plokhov, V. Sindeyev, and P. Reshedko, Coated Metal: Structure and Properties of MetalCoating Compositions, Springer, Berlin, Germany, 2002.

[9] F. C. Krebs, "Fabrication and processing of polymer solar cells: a review of printing and coating techniques," Solar Energy Materials and Solar Cells, vol. 93, no. 4, pp. 394-412, 2009.

[10] J. T. P. Derksen, F. P. Cuperus, and P. Kolster, "Renewable resources in coatings technology: a review," Progress in Organic Coatings, vol. 27, no. 1-4, pp. 45-53, 1996.

[11] J. D. Ranacourt, Optical Thin Films, Macmillan, New York, NY, USA, 1987.

[12] D. Lippkow and H. H. Strehblow, "Structural investigations of thin films of copper-selenide electrodeposited at elevated temperatures," Electrochimica Acta, vol. 43, no. 14-15, pp. 2131-2140, 1998.

[13] H. Kubota, M. Sato, and T. Miyazaki, "Anomalous temperature dependence of the giant magnetoresistance in $\mathrm{Ni} / \mathrm{Cu}$, $\mathrm{Ni}_{95} \mathrm{Co}_{5} / \mathrm{Cu}$ and $\mathrm{Ni}_{95} \mathrm{Fe}_{5} / \mathrm{Cu}$ multilayer films," Journal of Magnetism and Magnetic Materials, vol. 167, no. 1-2, pp. 1220, 1997.

[14] R. P. Raffaelle, T. Potdevin, A. F. Hepp, and S. G. Bailey, "Electrochemical synthesis of CuInSe $e_{2}$ for thin film devices," 
Materials Science in Semiconductor Processing, vol. 2, no. 4, pp. 289-296, 1999.

[15] N. Nancheva, P. Docheva, and M. Misheva, "Defects in Cu and $\mathrm{Cu}-\mathrm{O}$ films produced by reactive magnetron sputtering," Materials Letters, vol. 39, no. 2, pp. 81-85, 1999.

[16] N. A. M. Shanid and M. A. Khadar, "Evolution of nanostructure, phase transition and band gap tailoring in oxidized $\mathrm{Cu}$ thin films," Thin Solid Films, vol. 516, no. 18, pp. 6245-6252, 2008.

[17] I. Moreno, J. J. Araiza, and M. Avendano-Alejo, "Thin-film spatial filters," Optics Letters, vol. 30, no. 8, pp. 914-916, 2005.

[18] D. A. Glocker and S. I. Shah, Eds., Handbook of Thin Film Process Technology, Institute of Physics Publishing, Bristol, UK, 1998.

[19] M. Paunovic and M. Schlesinger, Fundamentals of Eelectrochemical Deposition, Wiley Interscience, New York, NY, USA, 2006.

[20] G. Staikov and A. Milchev, "The impact of electrocrystallization on nanotechnology," in Electrocrystallization in Nanotechnology, G. Staikov, Ed., Wiley VCH, Weinheim, Germany, 2007.

[21] W. Schwarzacher, "Electrodeposition: a technology for the future," Electrochemical Society Interface, vol. 15, no. 1, pp. 32-35, 2006.

[22] D. D. G. Jones and H. G. Masterson, Advances in Corrosion Science and Technology, vol. 1, Plenum Press, New York, NY, USA, 1970.

[23] D. D. Macdonald, Modern Aspects of Electrochemistry, vol. 11, Plenum Press, New York, NY, USA, 1975.

[24] J. L. Sudworth, Electrochemical Power Sources: Primary and Secondary Batteries, Peter Peregrinus, 1980.

[25] D. Dobrev, J. Vetter, and N. Angert, "Electrochemical preparation of metal microstructures on large areas of etched ion track membranes," Nuclear Instruments and Methods in Physics Research, Section B, vol. 149, no. 1-2, pp. 207-212, 1999.

[26] M. E. Hyde and R. G. Compton, "A review of the analysis of multiple nucleation with diffusion controlled growth," Journal of Electroanalytical Chemistry, vol. 549, pp. 1-12, 2003.

[27] J. Bard and L. R. Faulkner, Electrochemical Methods: Fundamentals and Applications, John Wiley and Sons, New York, NY, USA, 2001.

[28] J. W. P. Schmelzer, Nucleation Theory and Applications, Wiley VCH, Weinheim, Germany, 2005.

[29] E. Budevski, G. Staikov, and W. J. Lorenz, "Electrocrystallization Nucleation and growth phenomena," Electrochimica Acta, vol. 45, no. 15-16, pp. 2559-2574, 2000.

[30] J. W. Christian, The Theory of Transformations in Metals and Alloys, Pergamon Press, Budapest, Hungary, 1975.

[31] O. Kardos and D. G. Foulke, "Applications of Mass Transfer Theory: Electrodeposition on Small-Scale Profiles," in Advances in Electrochemistry and Electrochemical Engineering, C. W. Tobais, Ed., vol. 2, Interscience, New York, NY, USA, 1962.

[32] P. V. E. McClintock, D. J. Meredith, and J. K. Wigmore, Matter at Low Temperatures, Blackie \& Sons, Glasgow, UK, 1984.

[33] G. G. Wildgoose, D. Giovanelli, N. S. Lawrence, and R. G. Compton, "High-temperature electrochemistry: a review," Electroanalysis, vol. 16, no. 6, pp. 421-433, 2004.

[34] R. G. Chambers, "Cryophysics," Cryogenics, vol. 1, p. 119, 1960.
[35] I. I. Katkov, "Introduction to the field of cryobiology and overview of selected papers," International Journal of Refrigeration, vol. 29, no. 3, pp. 341-345, 2006.

[36] R. F. Rickard, C. Meyer, and D. A. Hudson, "Computational modeling of microarterial anastomoses with size discrepancy (small-to-large)," Journal of Surgical Research, vol. 153, no. 1, pp. 1-11, 2009.

[37] C. E. Banks, R. G. Evans, J. Rodrigues, P. G. Turner, T. J. Donohoe, and R. G. Compton, "Cryoelectrochemistry: electrochemical reduction of 2(RS)-methyl 1-(tertbutoxycarbonyl)-2-iodomethyl-2,5-dihydropyrrole-2carboxylate," Tetrahedron, vol. 61, no. 9, pp. 2365-2372, 2005.

[38] R. P. Van Duyne and C. N. Reilley, "Low-temperature electrochemistry. III. Application to the study of radical ion decay mechanisms," Analytical Chemistry, vol. 44, no. 1, pp. 158-169, 1972.

[39] S. Zein El Abedin, A. Y. Saad, H. K. Farag, N. Borisenko, Q. X. Liu, and F. Endres, "Electrodeposition of selenium, indium and copper in an air- and water-stable ionic liquid at variable temperatures," Electrochimica Acta, vol. 52, no. 8, pp. 27462754, 2007.

[40] Z. Zainal, A. Kassim, M. Z. Hussein, and C. H. Ching, "Effect of bath temperature on the electrodeposition of copper tin selenide films from aqueous solution," Materials Letters, vol. 58, no. 16, pp. 2199-2202, 2004.

[41] S. M. S. I. Dulal, H. J. Yun, C. B. Shin, and C. K. Kim, "Electrodeposition of CoWP film. III. Effect of $\mathrm{pH}$ and temperature," Electrochimica Acta, vol. 53, no. 2, pp. 934-943, 2007.

[42] L. Zhang, Z. Chen, Y. Tang, and Z. Jia, "Low temperature cathodic electrodeposition of nanocrystalline zinc oxide thin films," Thin Solid Films, vol. 492, no. 1-2, pp. 24-29, 2005.

[43] O. Radovici, C. Vass, and I. Solacolu, "Some aspects of copper electrodeposition from pyrophosphate electrolytes," Electrodeposition and Surface Treatments, vol. 2, no. 4, pp. 263-273, 1974.

[44] H. H. Elsentriecy, K. Azumi, and H. Konno, "Effects of pH and temperature on the deposition properties of stannate chemical conversion coatings formed by the potentiostatic technique on AZ91 D magnesium alloy," Electrochimica Acta, vol. 53, no. 12, pp. 4267-4275, 2008.

[45] C. A. Marozzi and A. C. Chialvo, "Development of electrode morphologies of interest in electrocatalysis. Part 1: electrodeposited porous nickel electrodes," Electrochimica Acta, vol. 45, no. 13, pp. 2111-2120, 2000.

[46] T. Aerts, J. B. Jorcin, I. De Graeve, and H. Terryn, "Comparison between the influence of applied electrode and electrolyte temperatures on porous anodizing of aluminium," Electrochimica Acta, vol. 55, no. 12, pp. 3957-3965, 2010.

[47] E. Guaus and J. Torrent-Burgués, "Tin-zinc electrodeposition from sulphate-gluconate baths," Journal of Electroanalytical Chemistry, vol. 549, pp. 25-36, 2003.

[48] D. A. Porter, K. E. Easterling, and M. Y. Sherif, Phase Transformations in Metals and Alloys, CRC Press, Taylor \& Francis, Boca Raton, Fla ,USA, 3rd edition, 2009.

[49] J. H. Perpezko, "Principles of solidification," in Metals Handbook, D. M. Stefenescu, Ed., vol. 15, p. 99, ASTM International, Piketon, Ohio, USA, 1988.

[50] P. E. De Jongh, D. Vanmaekelbergh, and J. J. Kelly, " $\mathrm{Cu}_{2} \mathrm{O}$ : electrodeposition and characterization," Chemistry of Materials, vol. 11, no. 12, pp. 3512-3517, 1999. 
[51] R. Walker, "Ultrasonic agitation in metal finishing," in Advances in Sonochemistry, T. J. Mason, Ed., vol. 3, JAI Press, 1993.

[52] T. F. Connors and J. F. Rusling, "Ultrasonically-assisted electrocatalytic dechlorination of polychlorinated biphenyls," Chemosphere, vol. 13, no. 3, pp. 415-420, 1984.

[53] R. Penn, E. Yeager, and F. Hovorka, "Effect of ultrasonic waves on concentration gradients," Journal of the Acoustical Society of America, vol. 31, pp. 1372-1376, 1959.

[54] B. Gautheron, C. Degrand, and G. J. Tainturer, "Ultrasoundinduced electrochemical synthesis of the anions selenide (Se22-, Se2-), and telluride (Te22-, and Te2-)," Journal of the American Chemical Society, vol. 107, pp. 5579-5581, 1985.

[55] D. J. Walton, A. Chyla, J. P. Lorimer, T. J. Mason, and G. Smith, "Modifying effect of ultrasound upon the electrochemical oxidation of cyclohexanecarboxylate," Chemical Communications, no. 9, pp. 603-604, 1989.

[56] S. Mitragotri, "Healing sound: the use of ultrasound in drug delivery and other therapeutic applications," Nature Reviews Drug Discovery, vol. 4, no. 3, pp. 255-260, 2005.

[57] P. Lorimer and T. J. Mason, "The applications of ultrasound in electroplating," Electrochemistry, vol. 67, no. 9, pp. 924930, 1999.

[58] D. J. Walton, "Sonoelectrochemistry-the application of ultrasound to electrochemicalsystems," Arkivoc, vol. 2002, no. 3, pp. 198-218, 2002.

[59] K. S. Suslick, Ultrasound: Its Chemical, Physical, and Biological Effects, Wiley VCH, Weinheim, Germany, 1988.

[60] T. G. Leighton, The Acoustic Bubble, Academic Press, London, UK, 1994.

[61] B. Pugin, "Qualitative characterization of ultrasound reactors for heterogeneous sonochemistry," Ultrasonics, vol. 25, no. 1, pp. 49-55, 1987.

[62] P. R. Birkin and S. Silva-Martinez, "A study of the effect of ultrasound on mass transport to a microelectrode," Journal of Electroanalytical Chemistry, vol. 416, no. 1-2, pp. 127-138, 1996.

[63] T. G. Leighton, "Bubble population phenomena in acoustic cavitation," Ultrasonics: Sonochemistry, vol. 2, no. 2, pp. S123-S136, 1995.

[64] K. S. Suslick, W. B. McNamara III, and Y. Didenko, "Hot spot conditions during multi bubble conditions," in Sonochemistry and Sonolumincesence, L. A. Crum, T. J. Mason, J. Reisse, and K. S. Suslick, Eds., Kluwer, Dordrecht, The Netherlands, 1999.

[65] K. S. Suslick, Y. Didenko, M. M. Fang et al., "Acoustic cavitation and its chemical consequences," Philosophical Transactions of the Royal Society A, vol. 357, no. 1751, pp. 335-353, 1999.

[66] F. J. Del Campo, J. Melville, J. L. Hardcastle, and R. G. Compton, "Differential pulse and chronoamperometric studies of insonated systems: acoustic streaming and cavitational effects," Journal of Physical Chemistry A, vol. 105, no. 4, pp. 666-674, 2001.

[67] F. Marken, R. P. Akkermans, and R. G. Compton, "Voltammetry in the presence of ultrasound: the limit of acoustic streaming induced diffusion layer thinning and the effect of solvent viscosity," Journal of Electroanalytical Chemistry, vol. 415, no. 1-2, pp. 55-63, 1996.

[68] P. Cintas and J. L. Luche, "The sonochemical approach," Green Chemistry, vol. 1, no. 3, pp. 115-125, 1999.
[69] D. F. Gaitan and L. A. Crum, "Sonoluminescence from single bubbles (A)," Journal of the Acoustical Society of America, vol. 87, p. S141, 1990.

[70] L. S. Bernstein and M. R. Zakin, "Confined electron model for single-bubble sonoluminescence," Journal of Physical Chemistry, vol. 99, no. 40, pp. 14619-14627, 1995.

[71] L. S. Bernstein, M. R. Zakin, E. B. Flint, and K. S. Suslick, "Cavitation thermometry using molecular and continuum sonoluminescence," Journal of Physical Chemistry, vol. 100, no. 16, pp. 6612-6619, 1996.

[72] F. Lepoint-Mullie, D. DE. Pauw, T. Lepoint, P. Supiot, and R. Avni, "Nature of the "Extreme conditions" in single sonoluminescing bubbles," Journal of Physical Chemistry, vol. 100, no. 30, pp. 12138-12141, 1996.

[73] H. Y. Kwak and J. H. Na, "Physical processes for single bubble sonoluminescence," Journal of the Physical Society of Japan, vol. 66, no. 10, pp. 3074-3083, 1997.

[74] L. A. Crum, "Sonoluminescence," Physics Today, vol. 47, no. 9, pp. 22-29, 1994.

[75] S. J. Putterman, "Sonoluminescence: sound into light," Scientific American, vol. 272, no. 2, pp. 46-51, 1995.

[76] R. G. Compton, J. C. Eklund, and S. D. Page, "Sonovoltammetry: heterogeneous electron-transfer processes with coupled ultrasonically induced chemical reaction. The "SonoEC" reaction," Journal of Physical Chemistry, vol. 99, no. 12, pp. 4211-4214, 1995.

[77] C. F. Naude and A. T. Ellis, "On the mechanism of cavitation damage by non-hemispherical cavities collapsing in contact with a solid boundary," Journal of Basic Engineering, vol. 83, pp. 648-656, 1961.

[78] L. A. Crum, "Bubbles hotter than the sun," New Scientist, vol. 146, no. 1975 , pp. 36-40, 1995.

[79] C. Agra-Gutiérrez, J. L. Hardcastle, J. C. Ball, and R. G. Compton, "Anodic stripping voltammetry of copper at insonated glassy carbon-based electrodes: application to the determination of copper in beer," Analyst, vol. 124, no. 7, pp. 1053-1057, 1999.

[80] C. E. Banks and R. G. Compton, "Ultrasonically enhanced voltammetric analysis and applications: an overview," Electroanalysis, vol. 15, no. 5-6, pp. 329-346, 2003.

[81] F. Marken, J. C. Eklund, and R. G. Compton, "Voltammetry in the presence of ultrasound: can ultrasound modify heterogeneous electron transfer kinetics?" Journal of Electroanalytical Chemistry, vol. 395, no. 1-2, pp. 335-339, 1995.

[82] F. Marken, T. O. Rebbitt, J. Booth, and R. G. Compton, "The use of ultrasound in the enhancement of the deposition and detection of metals in anodic stripping voltammetry," Electroanalysis, vol. 9, no. 1, pp. 19-22, 1997.

[83] R. G. Compton, J. C. Eklund, F. Marken, T. O. Rebbitt, R. P. Akkermans, and D. N. Waller, "Dual activation: coupling ultrasound to electrochemistry-an overview," Electrochimica Acta, vol. 42, no. 19, pp. 2919-2927, 1997.

[84] H. A. O. Hill, Y. Nakagawa, F. Marken, and R. G. Compton, "Voltammetry in the presence of ultrasound: sonovoltammetric detection of cytochrome $c$ under very fast mass transport conditions," Journal of Physical Chemistry, vol. 100, no. 43, pp. 17395-17399, 1996.

[85] N. Moriguchi, "The effect of supersonic waves on chemical phenomena (III): The effect on concentration polarization," Journal of the Chemical Society of Japan, vol. 55, 1934.

[86] E. L. Cooper and L. A. Coury, "Mass transport in sonovoltammetry with evidence of hydrodynamic modulation from ultrasound," Journal of the Electrochemical Society, vol. 145, no. 6, pp. 1994-1999, 1998. 
[87] R. Chow, R. Blindt, R. Chivers, and M. Povey, "The sonocrystallisation of ice in sucrose solutions: primary and secondary nucleation," Ultrasonics, vol. 41, no. 8, pp. 595604, 2003.

[88] G. Ruecroft, D. Hipkiss, T. Ly, N. Maxted, and P. W. Cains, "Sonocrystallization: the use of ultrasound for improved industrial crystallization," Organic Process Research and Development, vol. 9, no. 6, pp. 923-932, 2005.

[89] P. W. Cains, P. D. Martin, and C. J. Price, "The use of ultrasound in industrial chemical synthesis and crystallization. 1. Applications to synthetic chemistry," Organic Process Research and Development, vol. 2, no. 1, pp. 34-48, 1998.

[90] P. R. Gogate, R. K. Tayal, and A. B. Pandit, "Cavitation: a technology on the horizon," Current Science, vol. 91, no. 1, pp. 35-46, 2006.

[91] M. E. Hyde and R. G. Compton, "How ultrasound influences the electrodeposition of metals," Journal of Electroanalytical Chemistry, vol. 531, no. 1, pp. 19-24, 2002.

[92] C. E. Banks, R. G. Compton, A. C. Fisher, and I. E. Henley, "The transport limited currents at insonated electrodes," Physical Chemistry Chemical Physics, vol. 6, no. 12, pp. 31473152, 2004.

[93] S. Floate, M. Hyde, and R. G. Compton, "Electrochemical and AFM studies of the electrodeposition of cobalt on glassy carbon: an analysis of the effect of ultrasound," Journal of Electroanalytical Chemistry, vol. 523, no. 1-2, pp. 49-63, 2002.

[94] F. Touyeras, J. Y. Hihn, X. Bourgoin, B. Jacques, L. Hallez, and V. Branger, "Effects of ultrasonic irradiation on the properties of coatings obtained by electroless plating and electro plating," Ultrasonics Sonochemistry, vol. 12, no. 1-2, pp. 13-19, 2005.

[95] S. Ghasemi, M. F. Mousavi, M. Shamsipur, and H. Karami, "Sonochemical-assisted synthesis of nano-structured lead dioxide," Ultrasonics Sonochemistry, vol. 15, no. 4, pp. 448455, 2008.

[96] V. Mancier, A. L. Daltin, and D. Leclercq, "Synthesis and characterization of copper oxide (I) nanoparticles produced by pulsed sonoelectrochemistry," Ultrasonics Sonochemistry, vol. 15, no. 3, pp. 157-163, 2008.

[97] C. T. Walker and R. Walker, "Effect of ultrasonic agitation on some properties of electrodeposits," Electrodeposition and Surface Treatments, vol. 1, no. 6, pp. 457-469, 1973.

[98] T. Ohsaka, M. Isaka, K. Hirano, and T. Ohishi, "Effect of ultrasound sonication on electroplating of iridium," Ultrasonics Sonochemistry, vol. 15, no. 4, pp. 283-288, 2008.

[99] F. Touyeras, J. Y. Hihn, M. L. Doche, and X. Roizard, "Electroless copper coating of epoxide plates in an ultrasonic field," Ultrasonics Sonochemistry, vol. 8, no. 3, pp. 285-290, 2001.

[100] J. W. Christian, Transformations in Metals and Alloys, Pergamon Press, Budapest, Hungary, 1975.

[101] I. V. Markov, Crystal Growth for Beginners, World Scientific, Singapore, 2004.

[102] R. Chow, R. Blindt, R. Chivers, and M. Povey, "A study on the primary and secondary nucleation of ice by power ultrasound," Ultrasonics, vol. 43, no. 4, pp. 227-230, 2005.

[103] A. Mallik and B. C. Ray, "Morphological study of electrodeposited copper under the influence of ultrasound and low temperature," Thin Solid Films, vol. 517, no. 24, pp. 66126616, 2009.
[104] J. S. Santos, R. Matos, F. Trivinho-Strixino, and E. C. Pereira, "Effect of temperature on Co electrodeposition in the presence of boric acid," Electrochimica Acta, vol. 53, no. 2, pp. 644-649, 2007.

[105] S. Zein El Abedin, A. Y. Saad, H. K. Farag, N. Borisenko, Q. X. Liu, and F. Endres, "Electrodeposition of selenium, indium and copper in an air- and water-stable ionic liquid at variable temperatures," Electrochimica Acta, vol. 52, no. 8, pp. 27462754, 2007.

[106] P. M. S. Monk, Fundamentals of Electro-Analytical Chemistry, John Wiley and Sons, New York, NY, USA, 2008.

[107] T. Erdey-Gruz and M. Volmer, "Zur Theorie der Wasserstoffüberspannung," Zeitschrift fur Physikalische Chemie A, vol. 150, p. 203, 1930.

[108] T. Erdey-Gruz and M. Volmer, “Zm' Frage der elektrolytischen Metalliiberspannung," Zeitschrift fur Physikalische Chemie A, vol. 157, p. 165, 1931.

[109] J. A. V. Butler, "Studies in heterogeneous equilibria. Part III. A kinetic theory of reversible oxidation potentials at inert electrodes," Transactions of the Faraday Society, vol. 19, pp. 734-739, 1924.

[110] J. A. V. Butler, "The mechanism of overvoltage and its relation to the combination of hydrogen atoms at metal electrodes," Transactions of the Faraday Society, vol. 28, pp. 379-382, 1932.

[111] D. Pletcher, R. Greff, R. Peat, L. M. Peter, and J. Robinson, Instrumental Methods in Electrochemistry, Woodhead Publishing Limited, Cambridge, UK, 2001.

[112] D. Grujicic and B. Pesic, "Electrodeposition of copper: the nucleation mechanisms," Electrochimica Acta, vol. 47, no. 18, pp. 2901-2912, 2002.

[113] L. H. Mendoza-Huízar, C. H. Rios-Reyes, and M. G. GómezVillegas, "Zinc electrodeposition from chloride solutions onto glassy carbon electrode," Journal of the Mexican Chemical Society, vol. 53, no. 4, pp. 243-247, 2009.

[114] N. A. Pangarov and S. Rashkov, "Electrolytic deposition of alpha and beta cobalt," Comptes-Rendus de l'Académie Bulgare des Sciences, vol. 13, pp. 439-442, 1960.

[115] M. Fleischmann and H. R. Thirsk, "An investigation of electrochemical kinetics at constant overvoltage. The behaviour of the lead dioxide electrode. Part 5. The formation of lead sulphate and the phase change to lead dioxide," Transactions of the Faraday Society, vol. 51, pp. 71-95, 1955.

[116] D. J. Astley, J. A. Harrison, and H. R. Thirsk, "Electrocrystallization of mercury, silver and palladium," Transactions of the Faraday Society, vol. 64, pp. 192-201, 1968.

[117] B. Scharifker and G. Hills, "Electrochemical kinetics at microscopically small electrodes," Journal of Electroanalytical Chemistry, vol. 130, pp. 81-97, 1981.

[118] A. W. Ruff and K. G. Kreider, "Deposited thin-film wear sensors: materials and design," Wear, vol. 203-204, pp. 187195, 1997.

[119] D. A. Hardwick, "The mechanical properties of thin films: a review," Thin Solid Films, vol. 154, no. 1-2, pp. 109-124, 1987.

[120] G. C. A. M. Janssen, "Stress and strain in polycrystalline thin films," Thin Solid Films, vol. 515, no. 17, pp. 6654-6664, 2007.

[121] W. D. Nix and B. M. Clemens, "Crystallite coalescence: a mechanism for intrinsic tensile stresses in thin films," Journal of Materials Research, vol. 14, no. 8, pp. 3467-3473, 1999.

[122] M. T. Prado and J. J. Vlassak, "Microstructural evolution in electroplated Cu thin films," Scripta Materialia, vol. 47, no. 12, pp. 817-823, 2002. 
[123] V. A. Vas'Ko, I. Tabakovic, and S. C. Riemer, "Structure and room-temperature recrystallization of electrodeposited copper," Electrochemical and Solid-State Letters, vol. 6, no. 7, pp. C100-C102, 2003.

[124] H. Lee, S. S. Wong, and S. D. Lopatin, "Correlation of stress and texture evolution during self- and thermal annealing of electroplated Cu films," Journal of Applied Physics, vol. 93, no. 7, pp. 3796-3804, 2003.

[125] D. K. Gosser and Q. Huang, "Cryo-electrochemistry: new observations," Journal of Electroanalytical Chemistry, vol. 267, no. 1-2, pp. 333-338, 1989.

[126] T. J. Donohoe, D. J. Johnson, R. G. Compton, and J. D. Wadhawan, "Low temperature electrochemistry as a mechanistic probe for the partial reduction of heterocycles," Tetrahedron, vol. 60, no. 28, pp. 5945-5952, 2004.

[127] N. Fietkau, C. A. Paddon, F. L. Bhatti, T. J. Donohoe, and R. G. Compton, "Cryo-electrochemistry in tetrahydrofuran: the regioselective electrochemical reduction of a phenyl sulfone: fast-scan cyclic voltammetry investigations," Journal of Electroanalytical Chemistry, vol. 593, no. 1-2, pp. 131-141, 2006.

[128] C. A. Paddon, F. L. Bhatti, T. J. Donohoe, and R. G. Compton, "Cryo-electrochemistry in tetrahydrofuran: the electrochemical reduction of a phenyl thioether: [(3-[trans4-(methoxymethoxy)cyclohexyl] oxypropyl)thio]benzene," Journal of Electroanalytical Chemistry, vol. 589, no. 2, pp. 187-194, 2006.

[129] F. J. Del Campo, A. Neudeck, R. G. Compton, and F. Marken, "Low-temperature sonoelectrochemical processes: part 1. Mass transport and cavitation effects of $20 \mathrm{kHz}$ ultrasound in liquid ammonia," Journal of Electroanalytical Chemistry, vol. 477, no. 1, pp. 71-78, 1999.

[130] F. J. Del Campo, A. Neudeck, R. G. Compton, F. Marken, S. D. Bull, and S. G. Davies, "Low-temperature sonoelectrochemical processes-part 2: generation of solvated electrons and Birch reduction processes under high mass transport conditions in liquid ammonia," Journal of Electroanalytical Chemistry, vol. 507, no. 1-2, pp. 144-151, 2001.

[131] F. J. Del Campo, E. Maisonhaute, R. G. Compton, F. Marken, and A. Aldaz, "Low-temperature sonoelectrochemical processes-part 3. Electrodimerisation of 2nitrobenzylchloride in liquid ammonia," Journal of Electroanalytical Chemistry, vol. 506, no. 2, pp. 170-177, 2001.

[132] C. A. Paddon, C. E. Banks, I. G. Davies, and R. G. Compton, "Oxidation of anthracene on platinum macro- and microelectrodes: sonoelectrochemical, cryoelectrochemical and sonocryoelectrochemical studies," Ultrasonics Sonochemistry, vol. 13, no. 2, pp. 126-132, 2006.

[133] T. Ohsaka, M. Isaka, K. Hirano, and T. Ohishi, "Effect of ultrasound sonication on electroplating of iridium," Ultrasonics Sonochemistry, vol. 15, no. 4, pp. 283-288, 2008.

[134] C. Wang, L. Sun, H. Yun, J. Li, Y. Lai, and C. Lin, "Sonoelectrochemical synthesis of highly photoelectrochemically active $\mathrm{TiO}_{2}$ nanotubes by incorporating CdS nanoparticles," Nanotechnology, vol. 20, p. 5601, 2009. 


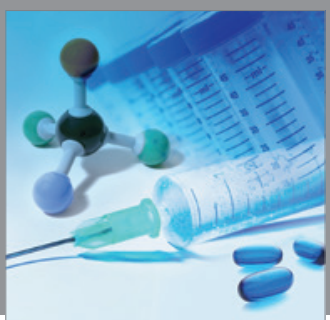

International Journal of

Medicinal Chemistry

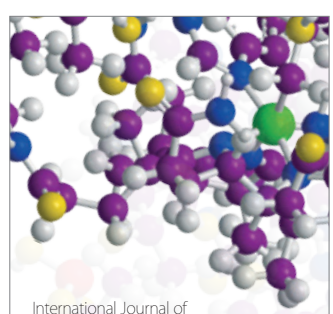

Carbohydrate Chemistry

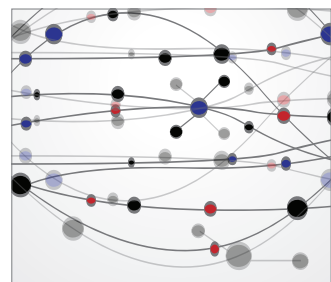

The Scientific World Journal
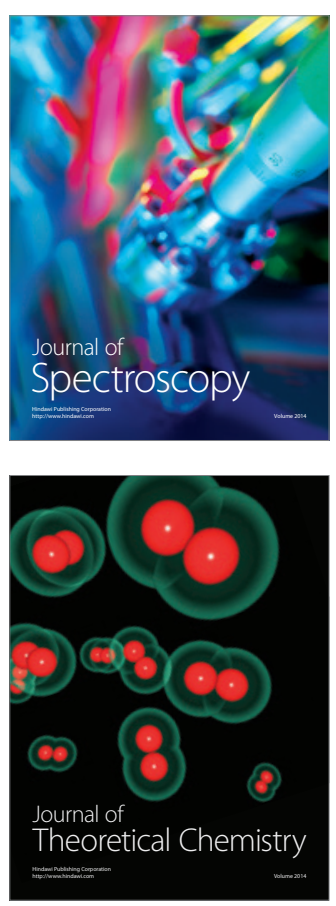
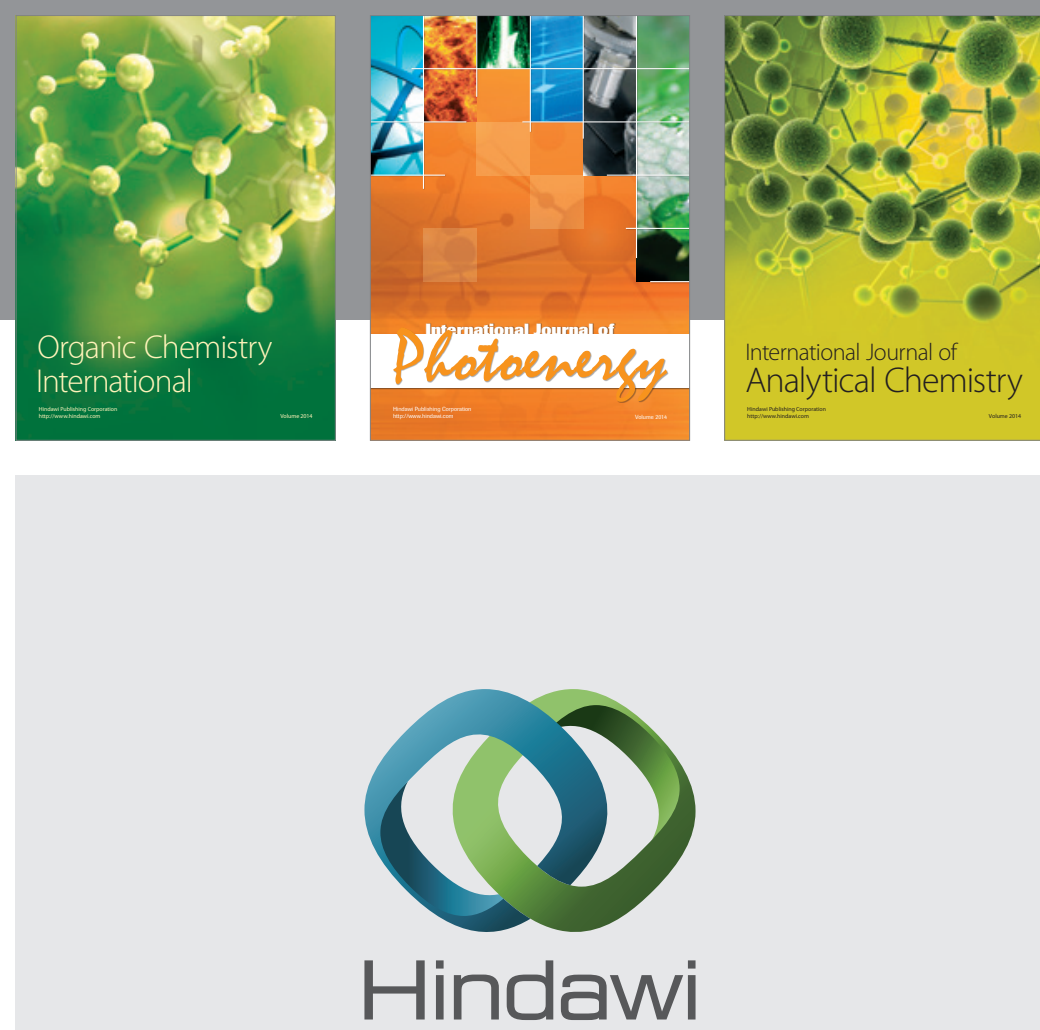

Submit your manuscripts at

http://www.hindawi.com
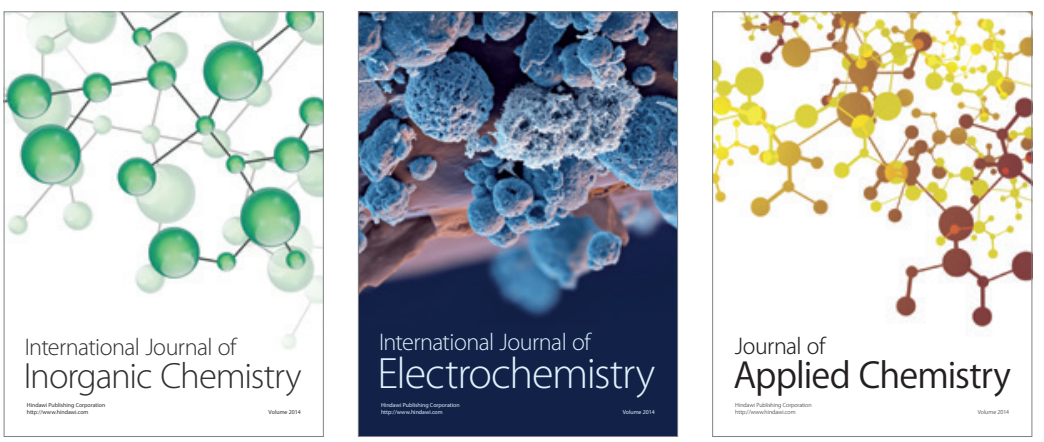

Journal of

Applied Chemistry
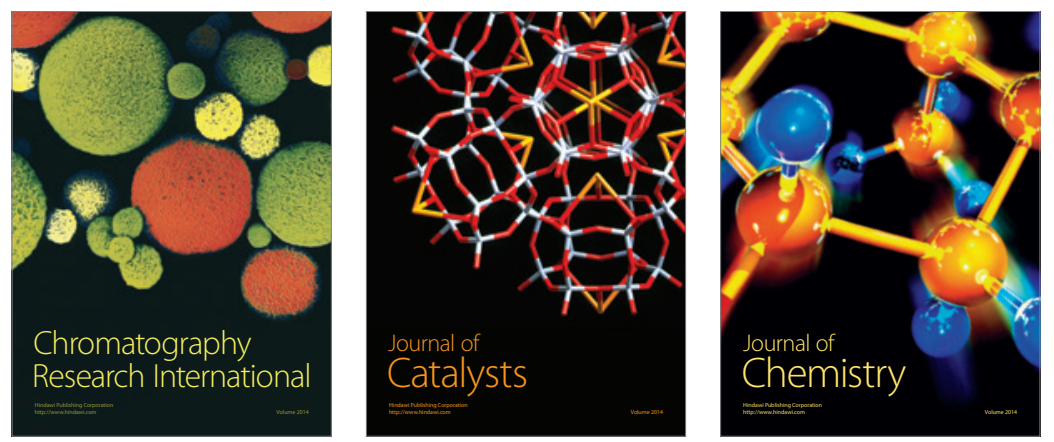
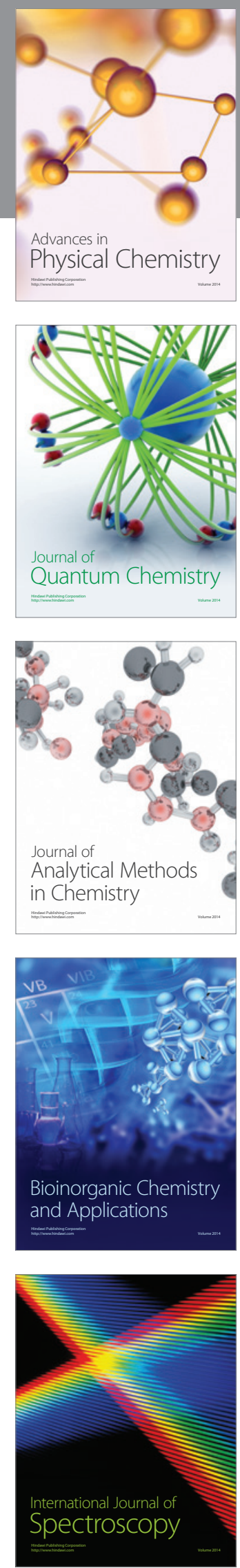